Federal Reserve Bank of Dallas

Globalization and Monetary Policy Institute

Working Paper No. 293

https://dallasfedcm.ws.frb.org/-/media/Documents/institute/wpapers/2016/0293.pdf

\title{
Financial Regulations and Price Inconsistencies across Bitcoin Markets*
}

\author{
Gina Pieters \\ Trinity University \\ Sofia Vivanco \\ Trinity University
}

December 2016

\begin{abstract}
We document systematic differences in bitcoin prices across 11 different markets representing $26 \%$ of global bitcoin trade volume. These differences must - due to the identical nature of all bitcoin - result from characteristics of markets themselves. We examine differences across the markets and find that those which do not require customer identification for establishing an account are more likely to deviate from representative market prices than those which do. This implies that standard financial regulations, specifically know-your-customer regulations, can have a non-negligible impact on the bitcoin market.
\end{abstract}

JEL codes: G12, G14, K42, L86

\footnotetext{
* Gina Pieters, Trinity University, Economics Department, 1 Trinity Place, San Antonio, TX 78212. gpieters@trinity.edu. Sofia Vivanco, Economics Department, 1 Trinity Place, San Antonio, TX 78212. This paper was written while Vivanco was an undergraduate at Trinity University. The views in this paper are those of the authors and do not necessarily reflect the views of the Federal Reserve Bank of Dallas or the Federal Reserve System.
} 


\section{Introduction}

Bitcoin is a homogeneous, virtual good that is completely identical across all the online markets in which it is sold. ${ }^{1}$ The markets that sell bitcoin ("bitcoin exchanges") operate 24 hours a day, 7 days a week, with pricing data available immediately and free of charge to anyone in the world with Internet access. Despite these properties, we find that bitcoin prices behave differently across markets; not all exchanges adhere to the law of one price (LOOP) - the theory that identical goods should sell for identical prices after trade costs are taken into consideration.

Should LOOP be expected of bitcoin prices? Whether bitcoin is considered a currency trading on international exchange rate markets or — as argued by Yermack (2015) — an asset trading on international financial markets, the answer is yes. Akram, Rime, and Sarno (2008) established the existence of LOOP in exchange rate markets, while Eun and Sabherwal (2003) established LOOP for internationally traded assets. Thus, if a bitcoin exchange fails to achieve LOOP, the cause must be associated with a characteristic of the exchange. We find bitcoin markets that consistently fail LOOP do not require customer identification to initiate an account, and therefore do not fully implement know-your-customer (KYC) policies. We are not aware of any other research that shows an impact by traditional financial regulations on bitcoin markets.

While there is no uniform, global regulatory framework for bitcoin - countries regulate or ignore bitcoin as they choose - most bitcoin regulations were implemented during 2013 or the beginning of 2014. The nature and extent of these regulations vary with some, such as Kaplanov (2012), debating the need for any regulation, envisioning a currency free of government intervention. The most recent bitcoin regulation announcement at the time of writing occurred on July 2014: Ecuador banned bitcoin, while the Isle of Mann merely clarified the application of existing tax rules. ${ }^{2}$ Within the USA, virtual currency exchanges are regulated by the Financial Crimes Enforcement Network (FinCEN), though individual states (e.g. New York) may adopt tougher measures. In March 2013, FinCEN classified bitcoin markets as be money transmitting businesses (MTB's), requiring exchanges to adopt anti-money-laundering (AML) and KYC policies. However, the global nature of bitcoin allows an exchange that trades bitcoin for US dollars to claim that it does not do business with the US consumers, and is therefore not subject to FinCEN's rulings. It is also feasible for an exchange to only selectively enforce a stated AML/KYC policy. King (2016) proposes a new framework to encourage financial institutions in the USA to incorporate bitcoin-based businesses (BBBs). A key element of this framework is the expectation that financial institutions ensure that the BBBs implement and enforce AML/KYC. Even though the global bitcoin regulatory environment is fractured, results from this paper

\footnotetext{
${ }^{1}$ Whether bitcoin is a currency, a good, or an asset is not relevant for this paper.

${ }^{2} \mathrm{~A}$ detailed discussion of the global regulatory environment can be found at http://www.coindesk.com/bitcoin-legal-map/ and http://www.coindesk.com/information/is-bitcoin-legal/
} 
imply that these policies may have an effect on the bitcoin market.

We provide a brief introduction to relevant bitcoin terminology and price research in Section 2. In Section 3 we summarize the behavior of bitcoin prices in US dollars across twelve price sources, and document the difference in levels both within and across exchanges depending upon which price-series is used. In Section 4, we document the failure of LOOP for several exchanges in our data. In Section 5 we examine the characteristics of each exchange, and show that all exchanges that fail LOOP do not require consumers to provide identification to establish an account. We find lower price deviations on exchanges that require identification, providing an explanation for these exchanges are more prone to LOOP failure. Section 6 concludes.

\section{A Brief Review Of Bitcoin}

This section provides the information needed to understand bitcoin for this paper; for a comprehensive overview of bitcoin, readers should consult Velde (2013). An accessible technical review of bitcoin can be found in Böhme, Christin, Edelman, and Moore (2015). Brandvold, Molnár, Vagstad, and Valstad (2015) contains a brief discussion of major events in bitcoin history, while White (2015) considers the market for crypto-currencies more broadly.

Bitcoin is a digital currency with no central issuing authority or physical form. ${ }^{3}$ More specifically, bitcoin is a cryptocurrency, a subset of digital currencies that use cryptography techniques to guide encryption protocols which identify ownership and verify transactions details. The bitcoin encryption protocol was outlined by the entity Nakamoto $(2008)^{4}$ and uniquely identifies each bitcoin within the bitcoin economy. Nakamoto created 21 million bitcoin, but did not release these into circulation. Instead, each bitcoin must be discovered by solving mathematical algorithms in a process called mining, examined by Kroll, Davey, and Felten (2013). Once mined, every bitcoin — or fraction thereof - can be sold, used as payment for retail purchases, or kept as an investment to be traded later. Bitcoin is bought and sold on trading websites known as "exchanges," each of which is independently operated and accessible 24 hours a day, 7 days a week to a global clientele.

It may seem strange that a completely virtual good could sustain a positive price. Dwyer (2015) showed that this phenomenon results from the limited availability and unique identification of each bitcoin. Luther (2016) shows that a requirement for this result is low transaction costs. Halaburda and Gandal (2014) show that, in its early establishment phase, the value of a cryptocurrency (of which bitcoin is but one

\footnotetext{
${ }^{3}$ Perspectives on whether bitcoin satisfies the economic definition of money can be found in Velde (2013), Lo and Wang (2014), and Yermack (2015), but do not impact the results of this paper.

${ }^{4}$ No one knows whether Nakamoto is an individual or a group, male or female, or actually Japanese.
} 
example) is determined by competition with other cryptocurrencies. This creates volatility in its initial price, but later transitions into pricing behavior consistent with use as a financial asset. This mechanism explains why Kristoufek (2013) finds a cointegrating relationship between bitcoin values and search queries on Google Trends and Wikipedia (potentially indicating a speculative bubble driven by curiosity), while Glaser, Zimmermann, Haferkorn, Weber, and Siering (2014) find that consumers' behavior is consistent with use of bitcoin as an investment vehicle. For investment purposes, Brière, Oosterlinck, and Szafarz (2015) show that bitcoin is an effective diversification asset.

Bitcoin has gained links to the physical goods economy over time as retailers-including Windows, Dell, Overstock, and gift card merchants-began accepting it as a form of payment, though not all use the same method. ${ }^{5}$ For example, Dell accepts direct bitcoin payments, but Amazon instead provides digital gift cards which may be purchased with bitcoin and then used to purchase goods on their website. Although a growing number of vendors accept bitcoin, both Ali, Barrdear, Clews, and Southgate (2014) and Greene and Shy (2014) conclude that digital currencies such as bitcoin do not currently have enough users to act as a general purchasing alternative to fiat currencies.

\section{About Bitcoin Prices}

\subsection{Bitcoin Data Collection}

We obtain the daily data for all exchanges that post prices in US dollars for a minimum 410 of the 426 days between 1 June 2014, and 31 July 2015, from www.bitcoincharts.com. ${ }^{6}$ This yields data from eleven exchanges $^{7}$ (Table 1), with price and volume statistics summarized in Table 2 and detailed exchange characteristics discussed in Section 5.1. We also collect data from Coindesk's Bitcoin Price Index, which aggregates prices from selected exchanges into a reference price-series. Linear interpolation is used in case of missing data-values. ${ }^{8}$

The data consist of the daily trade volume for each exchange, along with the Open, Close, High, Low, and Transaction-weighted prices. The BPI does not report Transaction-weighted price. In total we consider 59 price-series: five variants from each of the 11 exchanges, and four variants from the BPI. We examine all five variants to verify that the finding of this paper is a consistent feature of an exchange's prices. Bitcoin

\footnotetext{
${ }^{5}$ Websites such as coinmap (http://coinmap.org) or usebitcoins (usebitcoins.info) maintain lists of businesses-both online and physical - that accept bitcoin.

${ }^{6}$ All the studied exchanges have their bitcoin prices posted on the same aggregation website, and can therefore be simultaneously observed by all participants.

${ }^{7}$ One additional exchange, Cointrader, satisfies this selection criterion but is not included as it subsequently declared bankruptcy due to a hack.

${ }^{8}$ The price-series used as reference (BitFinex) and the exchanges with the most troubled price-series (LocalBitcoins and HitBTC), have no missing data values so linear interpolation is not driving the results of this paper.
} 
Table 1: Selected Bitcoin Exchanges

\begin{tabular}{|l|cc|l|}
\hline & \multicolumn{2}{|c|}{ Observations } & \\
Name & Initial & Interpolated & Website \\
\hline ANXBTC & 419 & 426 & https://anxbtc.com \\
BitFinex & 426 & 426 & https://www.bitfinex.com \\
BitKonan & 423 & 426 & https://bitkonan.com \\
BitStamp & 423 & 426 & https://www.bitstamp.net \\
BTC-e & 415 & 426 & https://btc-e.com \\
HitBTC & 426 & 426 & https://hitbtc.com \\
itBit & 426 & 426 & https://www.itbit.com \\
Kraken & 417 & 426 & https://www.kraken.com \\
LakeBTC & 414 & 414 & https://www.lakebtc.com \\
LocalBitcoins & 426 & 426 & https://localbitcoins.com \\
The Rock Trading & 420 & 426 & https://www.therocktrading.com \\
Bitcoin Price Index (BPI) & 426 & 426 & http://www.coindesk.com/price/ \\
\hline
\end{tabular}

exchanges operate 24 hours a day, 7 days a week, the close is the price of the last trade prior to 23:59:59 UTC, open is the price of the first trade after 00:00:00 UTC. We obtain data on the daily total global volume of bitcoin trades from https://blockchain.info. The BPI does not report a trade volume associated with its index price.

The data contain several clear outliers. For example, on 3 November 2014 the exchange LakeBTC reports a High price of $\$ 1000$ for one bitcoin. The highest LakeBTC price on the day preceding this transaction was $\$ 330.52$ and the highest price on August 2nd, the day following, was $\$ 329.67$. The average High price across all the other exchanges on November 3rd was $\$ 392.88$. Outliers could contribute towards a finding of LOOP failure if kept, and - given that determining whether outliers are bad data or an actual transaction price is beyond the scope of this paper - we remove them to minimize potential false identification. Outliers are replaced by the average of the adjacent prices on the exchange (in the example above, $\$ 1000$ is replaced by $\$ 330.10) .{ }^{9}$ Removing outliers with this method reduces the number of price deviations, and therefore biases the data against our main finding of non-LOOP behavior.

\subsection{Summary of Bitcoin Prices}

The Open price-series for each exchange is shown in Figure 1. Visually, the prices for all exchanges are similar, decreasing from a high of $\$ 600$, at the beginning of the sample, to a mid-sample low of approximately $\$ 200$, followed by a slow increase. The turning point does not correspond to a known event in bitcoin history, and the exact timing varies across exchanges. The LocalBitcoins price-series are clearly more volatile than other exchanges, but despite this follow the same trend as other exchanges. LocalBitcoins Transaction-weighted

\footnotetext{
${ }^{9}$ Significant outliers are defined as a price satisfying at least one of the following criteria: A price less than $\$ 1$ or greater than $\$ 3,000$; a percent change in daily price further than 10 standard deviations away from the mean of the changes for the series; or a price that doubles (or halves) then approximately returns to its original value the following day.
} 
Figure 1: Open USD Bitcoin Price
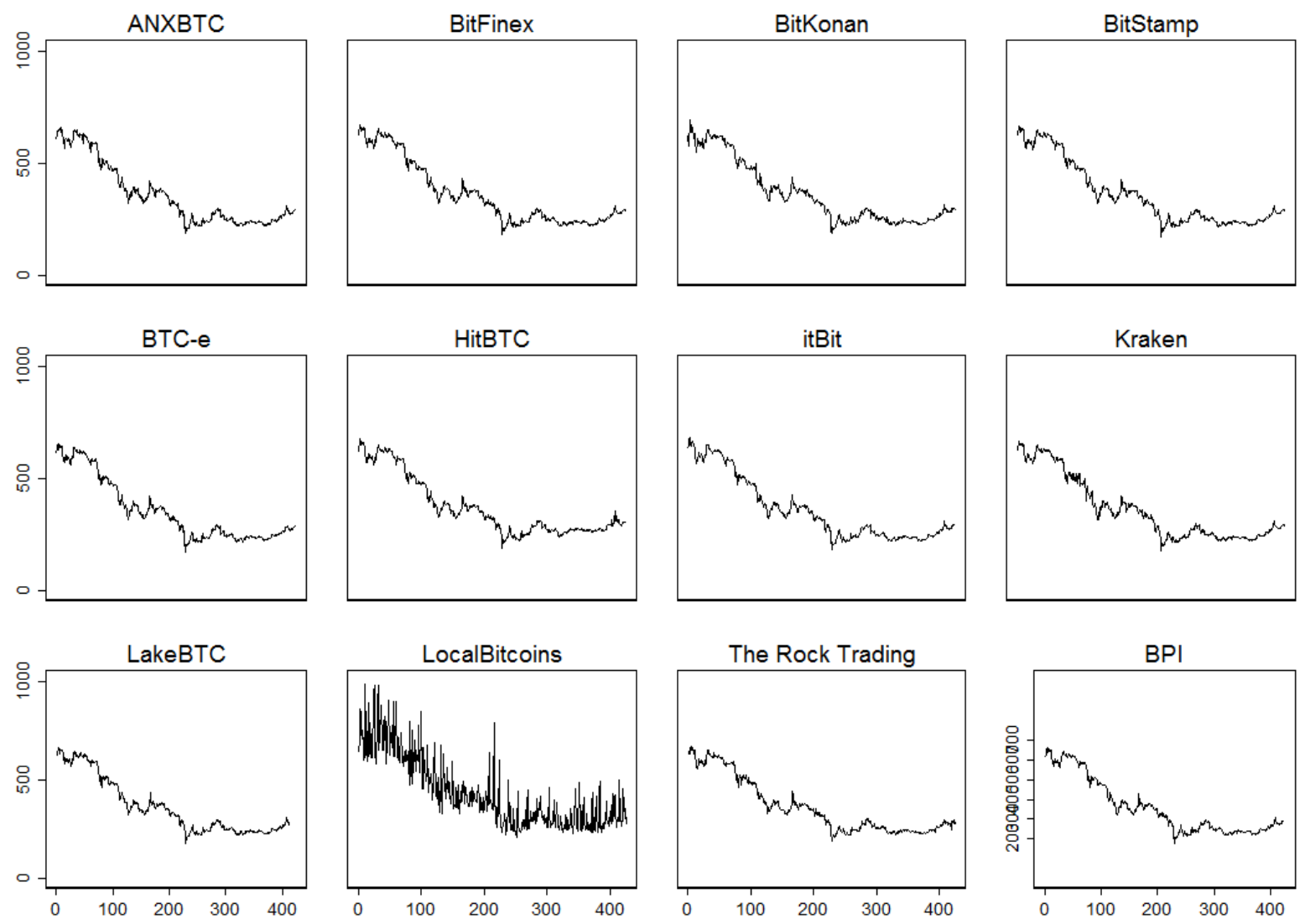

price displays a volatility comparable to other exchanges. ${ }^{10}$

The median daily Open, Close, High, Low, and Transaction-weighted price behavior across exchanges is summarized in Table 2. LocalBitcoins posts a median Open, Close, Weighted, and High price well above the other exchanges, while Low prices are below those of other exchanges. LocalBitcoins' median daily High/Low Price Premium (the difference between the High and Low price, relative to the Low price) is $136.75 \%$, easily the highest of all the exchanges (the second-highest is BitKonan, where the median daily High price is $6.12 \%$ above the Low price). ${ }^{11}$ It should come as no surprise that LocalBitcoins data will be found to be unrepresentative of bitcoin prices. It is less obvious from Table 2 that this distinction is shared by HitBTC as well. A comparison of bitcoin price levels is therefore not sufficient to identify exchanges that are not representative of the bitcoin market.

The remaining four columns of Table 2 compare the transaction volumes on each exchange relative to the estimated transaction volume across the entire bitcoin market, provided by Blockchain (www.blockchain.info,

\footnotetext{
${ }^{10}$ Series volatility is examined in Section A.1.

${ }^{11}$ Recall that outliers within each series were removed. Despite this, LocalBitcoins High prices are persistently higher, and its low prices persistently lower than other exchanges.
} 
Table 2: Median Price and Volume Characteristics Across Exchanges

\begin{tabular}{|l|ccccc|c|cc|cc|}
\hline & \multicolumn{4}{|c|}{ Price (USD) } & \multicolumn{2}{c|}{ High/Low } & \multicolumn{4}{c|}{ Transaction Volume } \\
& Open & Close & High & Low & Wei & Premium (\%) & BTC & $\%$ & USD & $\%$ \\
\hline ANXBTC & 315 & 314 & 321 & 296 & 314 & 4.84 & 856 & 0.53 & 255,944 & 0.52 \\
BitFinex & 315 & 314 & 320 & 304 & 312 & 4.26 & 17,511 & 11.25 & $5,580,123$ & 11.25 \\
BitKonan & 315 & 320 & 328 & 301 & 310 & 6.12 & 3 & 0.00 & 899 & 0.00 \\
BitStamp & 315 & 313 & 320 & 306 & 314 & 4.33 & 8,803 & 5.87 & $2,887,517$ & 5.87 \\
BTC-e & 312 & 311 & 315 & 304 & 311 & 3.79 & 5,990 & 4.09 & $1,883,258$ & 4.05 \\
HitBTC & 320 & 321 & 331 & 311 & 320 & 4.29 & 370 & 0.25 & 123,580 & 0.25 \\
itBit & 315 & 313 & 317 & 305 & 313 & 2.94 & 1,485 & 1.11 & 528,609 & 1.11 \\
Kraken & 315 & 314 & 320 & 305 & 316 & 3.75 & 10 & 0.00 & 3,457 & 0.00 \\
Lake & 322 & 321 & 330 & 315 & 319 & 3.21 & 3,865 & 2.69 & $1,309,233$ & 2.69 \\
LocalBitcoins & 386 & 381 & 1001 & 249 & 345 & 136.75 & 1,458 & 0.91 & 567,164 & 1.00 \\
TheRock & 317 & 313 & 335 & 312 & 316 & 2.05 & 10 & 0.00 & 3,051 & 0.00 \\
& & & & & & & & & - & - \\
BPI & 315 & 314 & 319 & 308 & - & 3.55 & - & - & - \\
BkCn & - & - & - & - & - & - & 160,353 & 100.00 & $48,689,795$ & 100.00 \\
\hline
\end{tabular}

Abbreviations: BkCn, Blockchain; BPI, Bitcoin Price Index; H/L, high/low ratio; Wei, transaction-weighted price.

BkCn). The share of global bitcoin trades and the share of USD trades in global bitcoin markets are similar, indicating that these exchanges all primarily trade in USD-BTC. The selected exchanges account for $26 \%$ of the USD-BTC trade volume during this time period. According to Bitcoincharts ${ }^{12}$, there are 72 active exchanges globally - though many do not trade in USD - thus, these eleven exchanges represent $15 \%$ of all exchanges. BitFinex is the largest exchange, representing a daily median of $11.25 \%$ of global bitcoin transactions, whereas the transaction volume of the smallest exchanges (BitKonan, Kraken, and The Rock Trading) are negligible on the scale of the global bitcoin market. ${ }^{13}$

\section{Investigating Law of One Price Between Exchanges}

Each bitcoin price-series contains a time trend, so we use a cointegration test to verify whether LOOP is satisfied. Given the price of bitcoin in two different markets, $m 1$ and $m 2$, a cointegration test determines if any linear combination of the price-series results in a stationary residual, $\epsilon_{t}:{ }^{14}$

$$
p_{t}^{m 1}-\beta p_{t}^{m 2}=\epsilon_{t}
$$

The cointegration test establishes whether a $\beta$ exists. If the two series do not cointegrate, then no linear combination can be found that results in a stationary residual and therefore the two series cannot obey the LOOP. If the two series cointegrate, LOOP requires that the long run linear cointegrating parameter, $\beta$,

\footnotetext{
${ }^{12}$ bitcoincharts.com/markets/list

${ }^{13}$ Like any currency, a bitcoin is divisible - A trade volume of 3 bitcoin does not correspond to a maximum of three trades of 1 bitcoin each. Currently, the smallest unit is called 1 bitcoin satoshi, a hundred-millionth of a bitcoin $\left(10^{-9}\right)$. Each exchange can determine the smallest trade it will accept.

${ }^{14}$ This definition is adopted from the purchasing power parity example in Greene (2007), Chapter 20.
} 
equals one: the two prices should be the same up to a constant. ${ }^{15}$ If it does not equal one, the two price-series display a statistically significant drift over the sample period.

\subsection{Method}

We first verify that both price-series are unit root, employing two tests with opposing null hypotheses for increased robustness. Our test with a null of the unit root is the Elliot et al. (1996) method of evaluating the Dickey-Fuller test (Dickey and Fuller, 1979) using generalized least squares (DFGLS). The test with a null of level stationarity is the Kwiatkowski-Phillips-Schmidt-Shin (KPSS) test (Kwiatkowski et al., 1992).

If both series are unit root, we apply the Johansen (1995) trace test to each at lag $\ell$. The Johansen trace test iteratively examines the hypothesis that $r$ or fewer cointegrating equations exist, with $r=0$ representing no cointegration. With two series, a cointegrating relationship is the simultaneous result that $r \leq 1$ is significant and $r=0$ is not. If the Johansen trace test finds cointegration, the cointegrating parameter can be estimated using a vector error correction model (VECM) with the vector of the bitcoin price $p_{m, t}$ for a given exchange $m$ and the reference series $r_{t}, \mathbf{P}_{m, t}=\left[p_{m, t}, r_{t}\right]$ :

$$
\Delta \mathbf{P}_{t}=\alpha \Pi^{\prime} \mathbf{P}_{t-1}+\sum_{i=1}^{\ell-1} \Gamma_{i} \Delta \mathbf{P}_{t-i}+\gamma+\epsilon_{t}
$$

where $\Delta \mathbf{P}_{t}=\mathbf{P}_{t}-\mathbf{P}_{t-1}$, and the market specific subscript on each term is omitted. The lag is first selected according to the Schwarz Bayesian information criterion (SBIC). The residual of the VECM model is evaluated for autocorrelation using a Lagrange Multiplier (LM) test as described in Johansen (1995). If autocorrelation is found, the lag is increased by one and the tests are repeated.

If at least one series is not unit root at the selected lag, the Johansen trace test cannot be applied. Instead, we apply the Pesaran et al. (2001) test (PSS). The PSS test allows for one series to be non-unit root, but requires a single direction of granger-causality between the series. Formally, the PSS bounds test is based on the unrestricted conditional error-correction model (CECM), expressed in notation of equation 2 as:

$$
\Delta p_{t}^{y}=\alpha+\sum_{i=1}^{\ell} \Gamma_{i} \Delta \mathbf{P}_{t-i}+\gamma \Pi^{\prime} \log \mathbf{P}_{t-1}+\omega^{\prime} \Delta p_{t}^{x}+\epsilon_{t}
$$

where $p_{t}^{x}$ refers to the exchange that granger-causes the prices on exchange $y, p_{t}^{y} \cdot{ }^{16}$ In cases where grangercausality is confirmed, BitFinex is usually identified as the granger-causing series. Given the presence of series that are not stationary, we use the methodology of Toda and Yamamoto (1995) (TY) to determine

\footnotetext{
${ }^{15}$ It is expected that $\epsilon \neq 0$ as each exchange has various fees, which should introduce an arbitrage band.

${ }^{16} \mathrm{Or}$, in the words of Pesaran et al. (2001), $p_{t}^{x}$ is the forcing function for $p_{t}^{y}$.
} 
Granger causality, first estimating a vector autoregression model (VAR) on the data with lags $\ell+1$ :

$$
\mathbf{P}_{t}=c+\sum_{i=1}^{\ell+1} \Psi_{i} \mathbf{P}_{t-i}+\epsilon_{t}
$$

where $\mathbf{P}_{t-(\ell+1)}$ is an exogenous variable. If we find residual autocorrelation at either $\ell$, the lag is incremented and the procedure repeated.

The long-run price-series relationship is captured in the coefficient $\Pi=[1,-\beta]$. If $\beta=1$, the market and the reference series perfectly share the same long-run trend. The typical size of the $99 \%$ confidence interval around $\beta$ is 0.03 , therefore $\beta \in[0.97,1.03]$ will be interpreted as showing LOOP.

\subsection{Long-Run Relationships}

The results from the unit root test, cointegration test, and long run cointegrating relationship for each priceseries are displayed in Table 3 and $4 .{ }^{17}$ The rows labeled "Unit Root?", "Cointegrated?", and "Law of One Price?" report whether the tests in the preceding rows confirm series unit root, series cointegration with BitFinex, and Law of One Price with BitFinex respectively. We use BitFinex, the largest bitcoin exchange, as the reference series. This does not imply that other exchanges are less valid or less important: BitStamp, the second-largest exchange, has a longer time series than BitFinex; BTC-e, the third largest exchange, was found to be a price leader by Brandvold et al. (2015). The CoinDesk Bitcoin Price Index (BPI), created by Quandl, reports bitcoin prices averaged across selected exchanges and may therefore be more robust to exchange-specific effects. ${ }^{18}$ We verify robustness using other series in section 4.3.1. The BitKonan Open, LocalBitcoins Weighted, and The Rock Trading Low price suffer from residual autocorrelation for all lags up to 15 , indicated by $\ell>15$, and are therefore not tested. The BPI does not have a Transaction-weighted price-series.

For any given exchange, LOOP findings in Tables 3 and 4 are the same for all tested price-series. The cause of LOOP failure is therefore not a characteristic that can be isolated to a single price-series, but is a general feature of an exchange. The price-series from HitBTC and LocalBitcoins consistently fail to attain LOOP with BitFinex. HitBTC fails as it does not have a cointegrating relationship with BitFinex while LocalBitcoins does cointegrate but does not obey LOOP.

Figure 2 is the difference between BitFinex and the series prices for LocalBitcoin and HitBTC - the two

\footnotetext{
${ }^{17} \mathrm{VECM}$ postestimation test results for eigenvalue stability are not included, but are consistent with well behaved series: There is one unit modulus, with all others strictly less than one.

${ }^{18}$ There are several shortcomings of the BPI, variants of which are shared by most bitcoin price indexes: it only posts bitcoin prices in US dollars, Euros, and Chinese yuan even though bitcoin is purchased using many currencies; the criteria for an exchange's initial selection is unknown, as are the details of the price averaging procedure; the BPI only posts open, close, high, and low prices, not a transaction-weighted price; and it does not provide trade volumes tailored to the price index it reports. Once selected, an exchange in the BPI must satisfy criteria described at CoinDesk (www.coindesk.com/bitcoin-price-index/).
} 
Table 3: Price Cointegration with BitFinex: Open and Close Prices

\begin{tabular}{|c|c|c|c|c|c|c|c|c|c|c|c|}
\hline & ANX & BitK & BitS & BTC-e & HitBTC & itBit & Kraken & Lake & Local & Rock & BPI \\
\hline \multicolumn{12}{|c|}{ OPEN } \\
\hline $\operatorname{Lag} \ell$ & 4 & $>15$ & 2 & 1 & 3 & 1 & 1 & 1 & 1 & 6 & 1 \\
\hline \multicolumn{12}{|l|}{ Unit Root Test } \\
\hline DFGLS & 0.30 & - & 0.34 & 0.31 & 0.18 & 0.29 & 0.27 & 0.29 & $-2.61^{* * *}$ & 0.33 & 0.21 \\
\hline KPSS & $7.17^{* * *}$ & - & $11.9^{* * *}$ & $17.7^{* * *}$ & $8.51^{* * *}$ & $17.8^{* * *}$ & $17.9^{* * *}$ & $17.7^{* * *}$ & $16.2^{* * *}$ & $5.2^{* * *}$ & $17.8^{* * *}$ \\
\hline Unit root? & Yes & - & Yes & Yes & Yes & Yes & Yes & Yes & No & Yes & Yes \\
\hline \multicolumn{12}{|c|}{ Cointegration Test } \\
\hline$r=0$ & 89 & - & 81 & 110 & $14^{* * *}$ & 136 & 202 & 111 & - & 35 & 110 \\
\hline$r \leq 1$ & $5.21^{* * * *}$ & - & $3.64^{* * *}$ & $3.28^{* * *}$ & 5.14 & $3.77^{* * * *}$ & $3.45^{* * *}$ & $3.22^{* * *}$ & - & $5.37^{* * *}$ & $3.44^{* * *}$ \\
\hline PSS & - & - & - & - & - & - & - & - & $180^{* * * *}$ & - & - \\
\hline Cointegrated? & Yes & - & Yes & Yes & No & Yes & Yes & Yes & Yes & Yes & Yes \\
\hline \multicolumn{12}{|c|}{ Long-Run Cointegrating Trend } \\
\hline$\beta$ & $1.00^{* * *}$ & - & $1.00^{* * *}$ & $0.99^{* * *}$ & - & $1.00^{* * *}$ & $1.01^{* * *}$ & $1.00^{* * *}$ & $1.14^{* * *}$ & $0.98^{* * *}$ & $1.00^{* * *}$ \\
\hline LOOP? & Yes & - & Yes & Yes & No & Yes & Yes & Yes & No & Yes & Yes \\
\hline \multicolumn{12}{|c|}{ CLOSE } \\
\hline $\operatorname{Lag} \ell$ & 1 & 3 & 7 & 5 & 3 & 2 & 4 & 5 & 4 & 1 & 5 \\
\hline \multicolumn{12}{|l|}{ Unit Root Test } \\
\hline DFGLS & 0.35 & -0.04 & 0.41 & 0.43 & 0.21 & 0.41 & 0.32 & 0.57 & -0.49 & 0.29 & 0.41 \\
\hline KPSS & $17.7^{* * *}$ & $8.93^{* * *}$ & $4.52^{* * *}$ & $5.96^{* * *}$ & $8.46^{* * *}$ & $11.8^{* * *}$ & $7.19^{* * *}$ & $5.96^{* * *}$ & $7.11^{* * *}$ & $17.9^{* * *}$ & $5.97^{* * *}$ \\
\hline Unit root? & Yes & Yes & Yes & Yes & Yes & Yes & Yes & Yes & Yes & Yes & Yes \\
\hline \multicolumn{12}{|c|}{ Cointegration Test } \\
\hline$r=0$ & 263 & 83 & 30 & 30 & $15^{* * *}$ & 84 & 53 & 32 & 90.37 & 208 & 29 \\
\hline$r \leq 1$ & $3.47^{* * *}$ & $5.62^{* * *}$ & $5.45^{* * *}$ & $4.56^{* * *}$ & 5.54 & $5.05^{* * *}$ & $4.27^{* * *}$ & $4.90^{* * *}$ & $4.71^{* * *}$ & $3.45^{* * *}$ & $5.45^{* * *}$ \\
\hline Cointegrated? & Yes & Yes & Yes & Yes & No & Yes & Yes & Yes & Yes & Yes & Yes \\
\hline \multicolumn{12}{|c|}{ Long-Run Cointegrating Trend } \\
\hline$\beta$ & $1.01^{* * *}$ & $0.98^{* * *}$ & $1.00^{* * *}$ & $0.99^{* * *}$ & - & $1.00^{* * *}$ & $1.00^{* * *}$ & $1.00^{* * *}$ & $1.13^{* * *}$ & $0.99^{* * *}$ & $1.00^{* * *}$ \\
\hline LOOP? & Yes & Yes & Yes & Yes & No & Yes & Yes & Yes & No & Yes & Yes \\
\hline
\end{tabular}

Abbreviations: ANX, ANXBTC; BitK, BitKonan; BitS, BitStamp; DFGLS, Dickey-Fuller with Generalized Least Squares; KPSS, Kwiatkowski-Phillips-Schmidt-Shin; Lake, LakeBTC; Local, LocalBitcoin; LOOP, law of one price; Rock, The Rock Trading. Significance: ${ }^{* * *} 1 \%,{ }^{* *} 5 \%,{ }^{*} 10 \%$.

series that failed to yield LOOP. ${ }^{19}$ The HitBTC differences are not stationary, visually confirming the lack of cointegration reported in Tables 3 and 4. Recall that LocalBitcoins cointegrates with BitFinex, but does not have LOOP, consistent with the observable trends in Figures $2 \mathrm{~b}, 2 \mathrm{~d}, 2 \mathrm{f}$, and $2 \mathrm{~g} .{ }^{20}$ The high volatility of LocalBitcoins - detected in price summaries presented Table 2 - is clearly visible.

\subsection{Robustness}

\subsubsection{Other Exchanges As The Reference Series}

We re-examine LocalBitcoins and HitBTC using the other exchanges as reference series, to evaluate whether the failure of LOOP could result from the decision to use BitFinex as a reference series. We apply all the methods of section 4.1, but unlike the detailed results in Tables 3 and 4, we report only the cointegrating parameter $\beta$ in Table 5. An $N C$ value indicates the Johansen test found no cointegration between the two series, $N G C$ indicates that a single direction of granger-causality could not be established when a series failed the unit root test. Results in Table 5 confirm that failure to find LOOP does not stem from using Bitfinex

\footnotetext{
${ }^{19} \mathrm{~A}$ trend line constructed using a Lowess smoother with a bandwidth of $40 \%$ is included to facilitate analysis of long run trends.

${ }^{20}$ For example, according the results in Table 4, the LocalBitcoins Low price difference, $p_{t}^{\text {Local,Low }}-p_{t}^{\text {BitFinex,Low }}$ graphed in Figure $2 \mathrm{~g}$ is not stationary (as required by LOOP), but $p_{t}^{\text {Local,Low }}-0.89 p_{t}^{\text {BitFinex,Low }}$ would be.
} 
Table 4: Price Cointegration with BitFinex: Weighted, High, and Low Prices

\begin{tabular}{|c|c|c|c|c|c|c|c|c|c|c|c|}
\hline & ANX & BitK & BitS & BTC-e & HitBTC & itBit & Kraken & Lake & Local & Rock & BPI \\
\hline \multicolumn{12}{|c|}{ WEIGHTED } \\
\hline Lag $\ell$ & 5 & 2 & 5 & 6 & 6 & 5 & 5 & 5 & $>15$ & 6 & - \\
\hline $\begin{array}{l}\text { Unit Root Test } \\
\text { DFGLS }\end{array}$ & 0.46 & 0.41 & & & & & & & & & \\
\hline $\begin{array}{l}\text { DFGLS } \\
\text { KPSS }\end{array}$ & $\begin{array}{l}0.46 \\
5.06 * * *\end{array}$ & $\begin{array}{c}0.41 \\
110^{* * *}\end{array}$ & 0.47 & 0.45 & 0.43 & 0.54 & 0.39 & 0.58 & - & 0.42 & - \\
\hline KPSS & $5.96^{* * *}$ & $11.9^{* * * *}$ & $5.99^{* * *}$ & $6.13^{* * *}$ & $4.91^{* * *}$ & $6^{* * *}$ & $6.02^{* * *}$ & $5.97^{* * *}$ & - & $5.21^{* * *}$ & - \\
\hline Unit root? & Yes & Yes & Yes & Yes & Yes & Yes & Yes & Yes & - & Yes & - \\
\hline \multicolumn{12}{|c|}{ Cointegration Test } \\
\hline$r=0$ & 53.12 & 119.11 & 48.27 & 23.79 & $11.54^{* * *}$ & 72.48 & 57.62 & 40.53 & - & 38.20 & - \\
\hline$r \leq 1$ & $4.62^{* * *}$ & $3.95^{* * *}$ & $5.34^{* * *}$ & $4.08^{* * *}$ & 4.82 & $5.57^{* * *}$ & $5.60^{* * *}$ & $4.91^{* * *}$ & - & $4.27^{* * *}$ & - \\
\hline Cointegrated? & Yes & Yes & Yes & Yes & No & Yes & Yes & Yes & - & Yes & - \\
\hline \multicolumn{12}{|c|}{ Long-Run Cointegrating Trend } \\
\hline$\beta$ & $1.00^{* * *}$ & $0.99^{* * *}$ & $1.01^{* * *}$ & $0.99^{* * *}$ & - & $1.00^{* * *}$ & $1.00^{* * *}$ & $1.00^{* * *}$ & - & $0.98^{* * *}$ & - \\
\hline LOOP? & Yes & Yes & Yes & Yes & No & Yes & Yes & Yes & - & Yes & - \\
\hline \multicolumn{12}{|c|}{ LOW } \\
\hline $\begin{array}{l}\text { Lag } \ell \\
\text { Unit Root Test }\end{array}$ & 5 & 1 & 1 & 5 & 5 & 4 & 5 & 2 & 1 & $>15$ & 1 \\
\hline \multicolumn{12}{|l|}{ Unit Root Test } \\
\hline DFGLS & 0.33 & -0.22 & 0.10 & 0.27 & 0.21 & 0.29 & 0.25 & 0.29 & -0.58 & - & -1.23 \\
\hline KPSS & $5.83^{\dagger}$ & $17.4^{\dagger}$ & $17.4^{\dagger}$ & $5.88^{\dagger}$ & $5.65^{\dagger}$ & $7.08^{\dagger}$ & $5.92^{\dagger}$ & $11.7^{\dagger}$ & $3.97^{\dagger}$ & - & $4.04^{\dagger}$ \\
\hline Unit root? & Yes & Yes & Yes & Yes & Yes & Yes & Yes & Yes & Yes & - & Yes \\
\hline \multicolumn{12}{|c|}{ Cointegration Test } \\
\hline$r=0$ & 44 & 150 & 185 & 39 & $16^{* * *}$ & 66 & 53 & 103 & 229 & - & 251 \\
\hline$r \leq 1$ & $4.78^{\dagger}$ & $3.49^{* * *}$ & $3.67^{* * *}$ & $4.53^{* * *}$ & 4.56 & $4.28^{* * *}$ & $5.27^{* * *}$ & $3.49^{* * * *}$ & $3.54^{* * *}$ & - & $3.64^{* * *}$ \\
\hline Cointegrated? & Yes & Yes & Yes & Yes & No & Yes & Yes & Yes & Yes & - & Yes \\
\hline \multicolumn{12}{|c|}{ Long-Run Cointegrating Trend } \\
\hline$\beta$ & $0.98^{\dagger}$ & $0.98^{\dagger}$ & $1.00 \dagger$ & $0.99^{* * *}$ & - & $1.00^{* * *}$ & $1.00^{* * *}$ & $1.00^{* * *}$ & $0.89^{* * *}$ & - & $1.00^{* * *}$ \\
\hline LOOP? & Yes & Yes & Yes & Yes & No & Yes & Yes & Yes & No & - & Yes \\
\hline \multicolumn{12}{|c|}{ HIGH } \\
\hline $\begin{array}{l}\text { Lag } \ell \\
\text { Unit Root Test }\end{array}$ & 5 & 1 & 4 & 1 & 3 & 1 & 2 & 1 & 1 & 3 & 5 \\
\hline DFGLS & 0.55 & 0.36 & 0.60 & 0.53 & 0.38 & 0.48 & 0.48 & 0.51 & $-8.19^{* * *}$ & 0.34 & 0.58 \\
\hline KPSS & $6.06^{* * *}$ & $18^{* * *}$ & $7.28^{* * *}$ & $18^{* * *}$ & $8.53^{* * *}$ & $17.9^{* * *}$ & $12.1^{* * *}$ & $17.9^{* * *}$ & $2.08^{* * *}$ & $9.3^{* * *}$ & $6.06^{* * *}$ \\
\hline Unit root? & Yes & Yes & Yes & Yes & Yes & Yes & Yes & Yes & No & Yes & Yes \\
\hline \multicolumn{12}{|c|}{ Cointegration Test } \\
\hline$r=0$ & 76 & 248 & 48 & 129 & $14.01^{* * *}$ & 133.45 & 115.57 & 107.99 & - & 60.69 & 36.84 \\
\hline$r \leq 1$ & $4.73^{* * *}$ & $4.97^{* * *}$ & $5.02^{* * *}$ & $4.98^{\dagger}$ & 5.67 & $5.53^{* * *}$ & $4.88^{* * *}$ & $4.74^{* * *}$ & - & $5.53^{* * *}$ & $5.21^{* * *}$ \\
\hline PSS & - & - & - & - & - & - & - & - & $60.78^{* * *}$ & - & - \\
\hline Cointegrated? & Yes & Yes & Yes & Yes & No & Yes & Yes & Yes & Yes & Yes & Yes \\
\hline \multicolumn{12}{|c|}{ Long-Run Cointegrating Trend } \\
\hline$\beta$ & $1.02^{* * *}$ & $0.99^{* * *}$ & $1.00^{* * *}$ & $0.98^{* * *}$ & - & $0.99^{* * *}$ & $1.00^{* * *}$ & $1.00^{* * *}$ & $1.06^{* * *}$ & $0.97^{* * *}$ & $0.99^{* * *}$ \\
\hline LOOP? & Yes & Yes & Yes & Yes & No & Yes & Yes & Yes & No & Yes & Yes \\
\hline
\end{tabular}

as the reference series. In all 90 cases where the reference series had LOOP with BitFinex, LocalBitcoins and HitBTC do not yield LOOP. ${ }^{21}$

We can establish market segmentation if the markets that do not satisfy LOOP with the reference series obey LOOP with each other. The relationship between LocalBitcoins and HitBTC exchanges is subtle: They are always cointegrated with each other, though they never obey LOOP with each other. Therefore, even though their price trends have more in common with each other than with BitFinex, they do not represent their own segmented market.

\footnotetext{
${ }^{21}$ LOOP results are transitive: all exchanges that adhere to LOOP with BitFinex also enjoy LOOP with each other.
} 
Figure 2: Price difference for series that failed LOOP

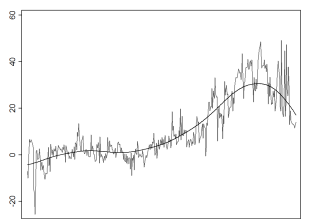

(a) Open, HitBTC

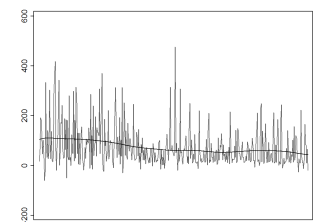

(b) Open, Local

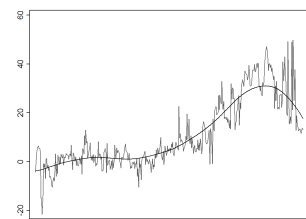

(c) Close, HitBTC

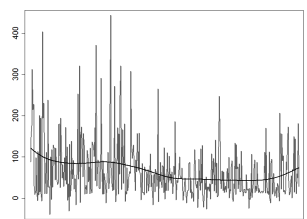

(d) Close, Local

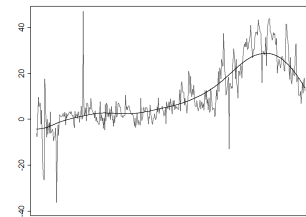

(e) Low, HitBTC

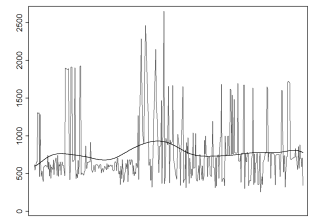

(f) High, Local

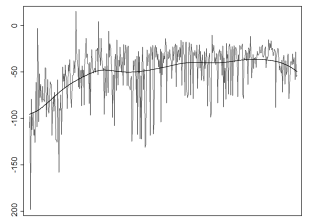

(g) Low, Local

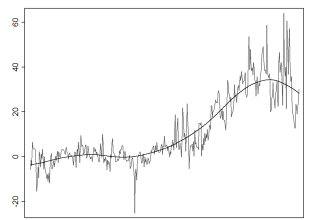

(h) High, HitBTC

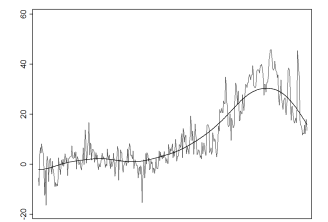

(i) Weighted, HitBTC

Table 5: Consistency of LOOP failure using other reference series

\begin{tabular}{|c|c|c|c|c|c|c|c|c|c|c|c|c|}
\hline & & \multicolumn{9}{|c|}{ Series with BitFinex LOOP } & \multicolumn{2}{|c|}{ Series w/o BitFinex LOOP } \\
\hline & BitFinex & ANX & BitK & BitS & BTC-e & itBit & Kraken & Lake & Rock & BPI & HitBTC & Local \\
\hline \multicolumn{13}{|c|}{ LocalBitcoin } \\
\hline Open & 1.14 & 1.14 & NGC & 1.14 & 1.16 & 1.14 & 1.13 & 1.14 & 1.15 & 1.15 & 1.21 & - \\
\hline Close & 1.13 & 1.13 & 1.13 & 1.13 & 1.14 & 1.13 & 1.14 & 1.13 & 1.15 & 1.14 & 1.20 & - \\
\hline Low & 0.89 & 0.91 & 0.91 & 0.90 & 0.91 & 0.90 & 0.89 & 0.89 & 0.90 & 0.90 & 0.95 & - \\
\hline High & 1.06 & NGC & 1.03 & 1.07 & NGC & NGC & NGC & NGC & NGC & NGC & NGC & - \\
\hline \multicolumn{13}{|l|}{ HitBTC } \\
\hline Open & $N C$ & $N C$ & $\ell>15$ & $N C$ & $N C$ & $N C$ & $N C$ & $N C$ & $N C$ & $N C$ & - & 1.21 \\
\hline Close & $N C$ & $N C$ & $N C$ & $N C$ & $N C$ & $N C$ & $N C$ & $N C$ & $N C$ & $N C$ & - & 0.84 \\
\hline Weighted & $N C$ & $N C$ & $N C$ & $N C$ & $N C$ & $N C$ & $N C$ & $N C$ & $N C$ & - & - & $\ell>15$ \\
\hline Low & $N C$ & 0.95 & $N C$ & $N C$ & 0.94 & $N C$ & 0.92 & $N C$ & $\ell>15$ & $N C$ & - & 1.06 \\
\hline High & $N C$ & $N C$ & 0.94 & $N C$ & $N C$ & 0.94 & $N C$ & $N C$ & $N C$ & $N C$ & - & NGC \\
\hline
\end{tabular}

All observations are significant at $1 \%$

Abbreviations: $\ell>15$, Lag to avoid residual autocorrelation greater than 15 days; NC, Not Cointegrated; NGC, Could not establish single direction granger-causality.

\subsubsection{Structural Breaks}

Visual examination of the series presented in Figures 1 and 2 reveals potential structural breaks occurring between mid-December, 2014 and mid-January, 2015. There is no known major event occurring within this time-period in bitcoin history. To verify that cointegration failure is not a result of a structural break, the sample is split into two sub-periods - the first 200 observations preceding 17 December 2014 (the "first segment"), and the final 176 observations after 5 February 2015 (the "second segment"). We again apply the methods from section 4.1 to each sub-segment. This division separates the decreasing and increasing sections of the price-series for all exchanges, as well as the observed "hump" for HitBTC in Figure 2, while retaining same-size sample within each segment across all exchanges. Results for all series are presented in Table 6, using BitFinex as the reference series and the same notation as Table 5 .

The results for HitBTC show that failure of LOOP in the full sample is caused by the behavior of the 
Table 6: Structural Break Cointegration with BitFinex

\begin{tabular}{|c|c|c|c|c|c|c|c|c|c|c|c|}
\hline & ANX & BitK & BitS & BTC-e & HitBTC & itBit & Kraken & Lake & Local & Rock & BPI \\
\hline \multicolumn{12}{|l|}{ Open } \\
\hline Full Sample & 1.00 & $\ell>15$ & 1.00 & 0.99 & $N C$ & 1.00 & 1.01 & 1.00 & 1.14 & 0.98 & 1.00 \\
\hline First Segment & 1.00 & 0.96 & 0.99 & 0.99 & 0.99 & 1.00 & 0.98 & 1.00 & 1.15 & 0.98 & 0.99 \\
\hline Second Segment & 1.01 & 1.01 & 0.99 & 0.91 & 0.84 & 0.99 & 1.01 & 0.97 & 0.88 & 0.93 & 0.98 \\
\hline \multicolumn{12}{|l|}{ Close } \\
\hline Full Sample & 1.01 & 0.98 & 1.00 & 0.99 & $N C$ & 1.00 & 1.00 & 1.00 & 1.12 & 0.99 & 1.00 \\
\hline First Segment & 1.00 & 0.95 & 0.99 & 0.99 & 0.99 & 1.00 & 0.98 & 0.99 & NGC & 0.99 & 0.99 \\
\hline Second Segment & 1.01 & 1.04 & 0.99 & 0.91 & $N C$ & 1.00 & 0.99 & 0.97 & 1.35 & 0.92 & 0.98 \\
\hline \multicolumn{12}{|l|}{ Weighted } \\
\hline Full Sample & 1.00 & 0.99 & 1.00 & 0.99 & $N C$ & 1.00 & 1.00 & 1.00 & $\ell>15$ & 0.98 & - \\
\hline First Segment & 1.01 & 0.97 & 1.00 & 0.99 & 1.00 & 1.00 & 0.99 & 1.00 & 1.05 & 0.98 & - \\
\hline Second Segment & $N C$ & 1.04 & 1.00 & 0.91 & $N C$ & 0.99 & 1.01 & 0.97 & 1.04 & 0.93 & - \\
\hline \multicolumn{12}{|l|}{ Low } \\
\hline Full Sample & 0.98 & 0.98 & 1.00 & 0.99 & $N C$ & 1.00 & 1.00 & 1.00 & 0.89 & $\ell>15$ & 1.00 \\
\hline First Segment & 0.99 & 0.96 & 0.99 & 0.99 & 0.99 & 1.01 & 0.98 & 1.00 & 0.88 & 1.00 & 0.99 \\
\hline Second Segment & 1.02 & 1.01 & 1.01 & 0.92 & $N C$ & 0.98 & 0.98 & 0.96 & 0.80 & 0.86 & $N C$ \\
\hline \multicolumn{12}{|l|}{ High } \\
\hline Full Sample & 1.02 & 0.99 & 1.00 & 0.98 & $N C$ & 0.99 & 1.00 & 1.00 & NGC & 0.97 & 0.99 \\
\hline First Segment & 1.03 & 0.97 & 0.99 & 0.99 & 1.00 & 1.00 & 0.98 & 0.99 & NGC & 0.95 & 0.99 \\
\hline Second Segment & 1.02 & 1.02 & 0.99 & 0.89 & $N C$ & 1.00 & 1.00 & 0.97 & $\mathrm{NC}$ & 0.97 & 0.97 \\
\hline
\end{tabular}

All observations are significant at $1 \%$

Abbreviations: $\ell>15$, Lag to avoid residual autocorrelation greater than 15 days; NC, Not Cointegrated;

NGC, Could not establish single direction granger-causality.

second segment; the first segment does satisfy LOOP. There are no publicly stated reasons that could explain this turning point for HitBTC. This is additional evidence that failure of LOOP is not caused by market segmentation between exchanges: LocalBitcoins fails LOOP in both segments. ${ }^{22}$

BitKonan and Rock Trading illustrate that structural issues such as autocorrelation (indicated by $\ell>15$ in the full sample) may point to trend changes within the sample (the Low price result for Rock Trading shows a clear change in the cointegration parameter for the two periods), but not necessarily so (the $\beta$ parameter for the LocalBitcoin Transaction-weighted price is relatively stable). This could reflect limitations inherent in the significantly reduced sample size, diminishing our ability to establish additional conclusions.

The differences in the $\beta$ parameter for the shorter sample is greater than the full series, making verification of LOOP harder. The second segment of BitKonan Low prices clearly fails LOOP with a $\beta$ of 0.85 , but how should we regard LakeBTC's Low $\beta$ of 0.96 ? Given that the $99 \%$ confidence interval around LakeBTC is $[0.93,0.99]$, a $\beta=1$ is statistically unlikely. We shall classify an exchange containing at least one segment with $\beta \notin[0.90,1.10]$ as displaying "Strong LOOP Failure", while an exchange containing $\beta \in[0.90,1.10]$ but $\beta \notin[0.97,1.03]$ displays "Weak LOOP Failure". There are therefore four exchanges that have no LOOP failure: ANXBTC, BitStamp, itBit, and Kraken, as well as the BPI. Two exchanges (LakeBTC and

\footnotetext{
${ }^{22}$ We emphasize that data from LocalBitcoins and HitBTC should not be avoided per se, rather that the nature of bitcoin exchanges requires initial testing to verify that a price-series is representative.
} 
BitKonan) have "Weak LOOP Failure", while two more (The Rock Trading and BTC-e) have "Strong LOOP Failure". LocalBitcoins and HitBTC display "Consistent LOOP Failure" as they do not achieve LOOP over the full sample.

\section{Exchange Characteristics and Bitcoin Pricing Behavior}

The preceding section identifies the extent to which bitcoin exchanges may — or may not — be representative of bitcoin price trends. In this section, we examine the extent to which differences in prices may be explained by characteristics of the exchanges.

\subsection{Exchange Characteristics}

Table 7 summarizes select characteristics of the 11 exchanges across three categories: fees, exchange transparency, and regulations. Additional notes are in italics. BPI is not an exchange and is not included.

Table 7: Characteristics of Bitcoin Exchanges

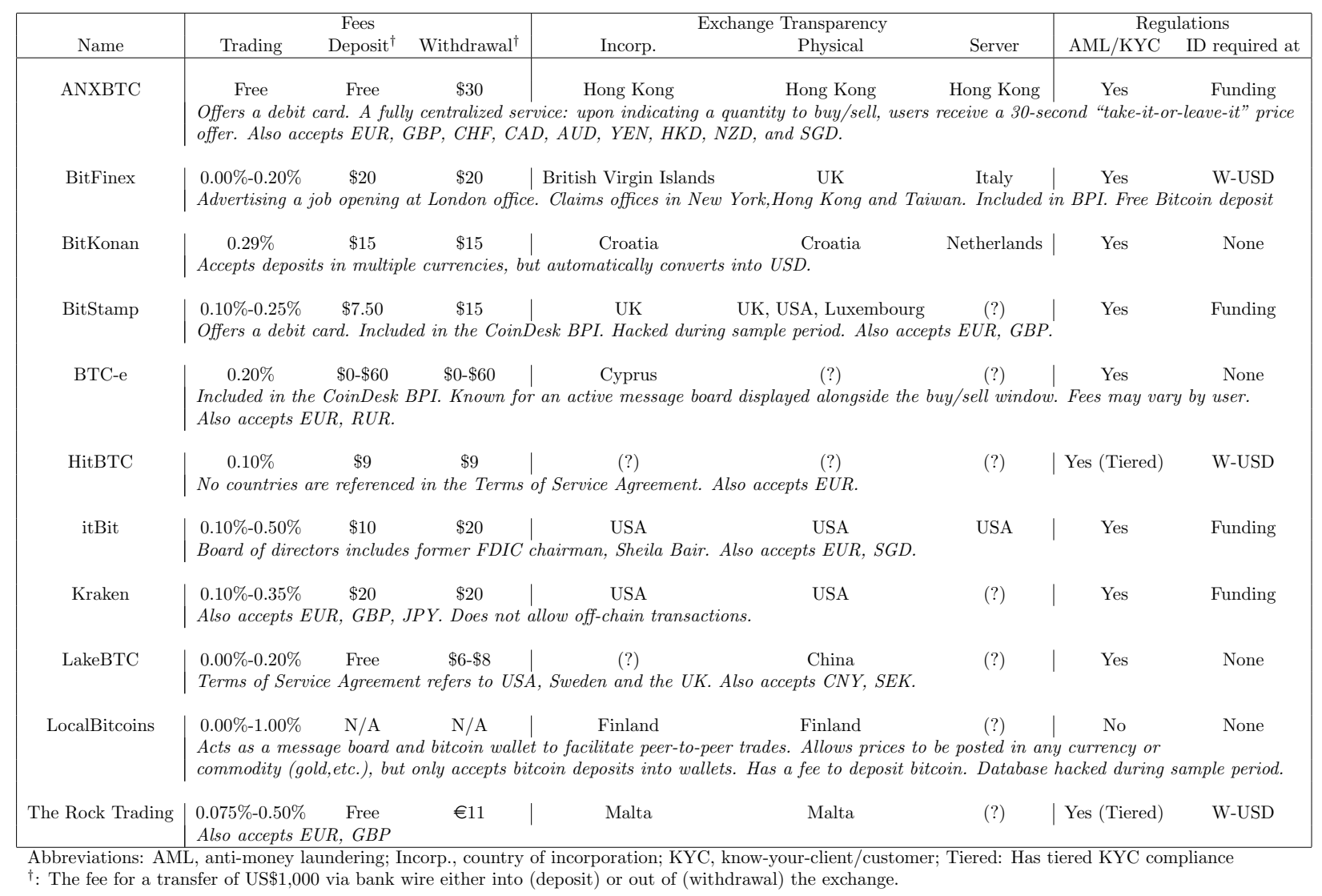

The "Fees" columns summarize various fees across the exchanges. Fees typically depend on trade volume, with most trading fees between $0 \%$ to $0.50 \%$. LocalBitcoins is unusual in that it charges no fee for buying, 
and a $1 \%$ fee for selling bitcoin, regardless of volume. Deposit and withdrawal fees are calculated for a transfer of US $\$ 1,000$ via bank wire. ${ }^{23}$ LocalBitcoins - which does not accept currency deposits- has no currency transfer fees. Most exchanges charge a higher fee for withdrawals than deposits.

The next section in Table 7 represent measures of an exchange's transparency: is it even possible to determine which country's laws the exchange should follow? The country of incorporation ("Incorp.") is determined by the laws referenced in the exchange's Terms of Service. The physical location ("Physical") reflects either a mailing address or the location of an advertised job opening. Job location may be misleading as employees may telecommute, while the mailing address may be for a holding company. Finally, we also report server location ("Server") as this may be a better indicator of the physical location of the exchange's headquarters. It is rare that a country of incorporation cannot be determined. The physical address usually reflects the country of incorporation, although it may be different (BitFinex). Most exchanges refuse to reveal their server locations. The available data reveals the global diversity of bitcoin exchanges, with 11 exchanges revealing known connections to 12 countries.

The final pair of columns ("Regulations") are measures of an exchange's adherence to AML/KYC. The functional details required to adhere to AML/KYC may vary, but broadly speaking KYC adherence involves collecting data to verify the identity of an account holder (drivers license, passport, etc.), while AML requires that an exchange monitor transaction data to identify suspicious behavior. "AML/KYC" indicates whether an exchange has a statement that implies that it adheres to AML/KYC. Some exchanges will state compliance to only AML policies, but their description of enforcement includes collecting passport or ID photos, which we interpret as evidence of a KYC policy, even if it not stated as such.

It is possible that an exchange claims it adheres to an AML/KYC policy, without effectively implementing one. While we cannot verify AML compliance, we can test an exchange's KYC adherence. We open accounts at each exchange in the sample to identify when (and if) an exchange attempts to gather KYC information. We make no attempt to hide the geographic location of the computer (USA) and indicate USA residency if prompted. Beyond the email address used to establish the account, we provide no additional information to the exchange. We attempt to fund each account with 0.01 bitcoin (approximately USD \$6), sell the bitcoin for USD, buy a replacement bitcoin on the exchange, and withdraw both USD and bitcoin. ${ }^{24}$

Four exchanges - ANXBTC, BitStamp, itBit, and Kraken - do not allow any transfers or transactions without identity verification, indicated by "Funding" in the final column in Table 7 . The remaining ex-

\footnotetext{
${ }^{23}$ Alternatives to bank wires that are accepted at some-but not all-exchanges are virtual payments (i.e., PayPal) or credit card funding (VISA, MasterCard). The bank wire fee may change based upon the value transferred.

${ }^{24}$ All bitcoin are sent from the same wallet at the exchange Coinbase, which is not an exchange in the study. We initiate (but do not complete) the procedure to withdraw the USD generated by the bitcoin sale due to legal and security concerns. USD withdrawals cannot occur on LocalBitcoins as it does not provide a platform for the transfer of currency. We do not sell the transferred bitcoin on LocalBitcoin due to legal and security concerns.
} 
changes allow the account to be funded with the bitcoin, sold for USD, and a replacement bitcoin to be purchased and withdrawn from the exchange. These exchanges differ, however, in regards to withdrawing USD. Three exchanges - BitKonan, BTC-e, and LakeBTC - would allow us to withdraw USD without providing additional information. It is possible that these three exchanges have a limit below which they do not require ID, and that the amount of USD we were attempting to withdraw was below this limit.

Exchanges differ in other, less quantifiable ways, noted in Table 7. The currencies accepted for bitcoin purchases vary across exchanges. ANXBTC and BitStamp offer a debit card. In addition to AML and KYC compliance, itBit secured a charter from the New York State Department of Financial Services and have appointed former FDIC chair Sheila Bair to their board of directors. Only one exchange, Kraken, states that it does not allow off-chaining - allowing transactions to complete prior to their integration into the blockchain. The remaining exchanges do not address when or how they reconcile off-chain transactions to the blockchain.

Most exchanges do not hold their own inventory of either currency or bitcoin, instead they match user with a buy (sell) to a user with an offer (bid). ANXBTC users, on the other hand, submit the number of bitcoin they wish to trade, and then have 30 seconds to accept a price offered by the ANXBTC exchange. In contrast, LocalBitcoins allows users to transfer bitcoin to another user's wallet, but does not provide a platform for the reciprocal transfer of currency. ${ }^{25}$ Instead, a LocalBitcoins user posts an offer with price and payment specifications on a LocalBitcoins posting board, which aggregates and lists all individual offers by username, price, and zip code. Examples of payment specifications include making a cash deposit at a specific bank branch, PayPal transfer, or a face-to-face meeting for a commodity swap (such as gold). Stop and limit orders are available on all exchanges except LocalBitcoin. Because it uses a posting board system, LocalBitcoins is one of the few exchanges where one user can single out another user with whom to conduct their transaction.

\subsection{Price trend and Exchange Characteristics}

In Section 1 we argued that it is not unreasonable to expect bitcoin to adhere to LOOP, and that LOOP failure of an exchange must result from a characteristic of that exchange rather than an inherent property of bitcoin. To evaluate which characteristics may contribute to our finding of non-LOOP exchanges, Table 8 groups exchanges by LOOP results, and summarize as indicator variables the exchange characteristics contained in Table 7 and trade volumes from Table 2. For example, if the exchange posts an AML/KYC statement "Stated AML/KYC" takes a value of 1. If an exchange requires additional information for a user to withdraw currency (whether that in the funding stage or the withdrawal stage), the "ID for W-Currency"

\footnotetext{
${ }^{25}$ As the LocalBitcoin platform does not transfer fiat currency, it maintains that it does not need to comply with AML/KYC.
} 
takes a value of 1 .

Free Fiat Deposits an indicator variable for fees, as it is uniform across all depositors regardless of currency, account size, transaction size, or transaction frequency. LocalBitcoins is the only exchange that does not have free bitcoin deposits. We also indicate whether exchanges have fixed trading fees ("Fixed Trading Fee"): A sliding trading fee typically rewards larger trades which may distort the market, especially if large trades allows users to avoid paying a trade fee altogether ("Free Trades Feasible"). Inclusion in the BPI is a proxy for an exchange's reputation in the bitcoin community. Several exchanges allow trades in currencies other than USD. Only Kraken states that it does not allow off-chain transactions, and only LocalBitcoins allows users to select who they wish to trade with ("Targeted Trading"). If any of the three locations associated with the exchange in located within the USA ("USA location?"), the exchange is legally required to comply with $\mathrm{AML} / \mathrm{KYC}$.

Table 8: Cointegration and Exchange Properties

\begin{tabular}{|c|c|c|c|c|c|c|c|c|c|c|}
\hline & \multicolumn{4}{|c|}{ Exchanges with LOOP } & \multicolumn{2}{|c|}{ Weak LOOP Fail } & \multicolumn{2}{|c|}{ Strong LOOP Fail } & \multicolumn{2}{|c|}{ Consistent LOOP Fail } \\
\hline & ANX & BitS & itBit & Kraken & BitK & Lake & BTC-e & Rock & HitBTC & Local \\
\hline \multicolumn{11}{|c|}{ Exchange Transparency (Table 7) } \\
\hline Known incorporation? & 1 & 1 & 1 & 1 & 1 & 0 & 1 & 1 & 0 & 1 \\
\hline Known physical address? & 1 & 1 & 1 & 1 & 1 & 1 & 0 & 1 & 0 & 1 \\
\hline Known server location? & 1 & 1 & 1 & 0 & 1 & 0 & 0 & 0 & 0 & 0 \\
\hline USA location? & 0 & 1 & 1 & 1 & 0 & 0 & 0 & 0 & 0 & 0 \\
\hline \multicolumn{11}{|c|}{ Regulation Compliance (Table 7) } \\
\hline Stated AML/KYC? & 1 & 1 & 1 & 1 & 1 & 1 & 1 & 1 & 1 & 0 \\
\hline ID for Funding & 1 & 1 & 1 & 1 & 0 & 0 & 0 & 0 & 0 & 0 \\
\hline ID for W-BTC & 1 & 1 & 1 & 1 & 0 & 0 & 0 & 0 & 0 & 0 \\
\hline ID for W-Currency & 1 & 1 & 1 & 1 & 0 & 0 & 0 & 1 & 1 & - \\
\hline \multicolumn{11}{|l|}{ Fees (Table 7) } \\
\hline Free Fiat Deposit & 1 & 0 & 0 & 0 & 0 & 1 & 0 & 1 & 0 & - \\
\hline Free Bitcoin Deposit & 1 & 1 & 1 & 1 & 1 & 1 & 1 & 1 & 1 & 0 \\
\hline Fixed Trading Fee & 1 & 0 & 0 & 0 & 1 & 0 & 1 & 0 & 1 & 0 \\
\hline Free Trades Feasible & 1 & 0 & 0 & 0 & 0 & 1 & 0 & 0 & 0 & 1 \\
\hline \multicolumn{11}{|c|}{ Share of Global Transactions (Table 2) } \\
\hline High $(>4 \%)$ & 0 & 1 & 0 & 0 & 0 & 0 & 1 & 0 & 0 & 0 \\
\hline Low $(\approx 0 \%)$ & 0 & 0 & 0 & 1 & 1 & 0 & 0 & 1 & 0 & 0 \\
\hline \multicolumn{11}{|c|}{ Other Characteristics (Table 2) } \\
\hline Included in BPI & 0 & 1 & 0 & 0 & 0 & 0 & 1 & 0 & 0 & 0 \\
\hline EUR trade & 1 & 1 & 1 & 1 & 0 & 0 & 1 & 1 & 1 & 1 \\
\hline GBP trade & 1 & 1 & 0 & 1 & 0 & 0 & 0 & 1 & 0 & 1 \\
\hline Non EUR/GBP fiat & 1 & 0 & 1 & 1 & 0 & 1 & 1 & 0 & 0 & 1 \\
\hline Hacked & 0 & 1 & 0 & 0 & 0 & 0 & 0 & 0 & 0 & 1 \\
\hline Debit Card Available & 1 & 1 & 0 & 0 & 0 & 0 & 0 & 0 & 0 & 0 \\
\hline Does not allow off-chaining & 0 & 0 & 0 & 1 & 0 & 0 & 0 & 0 & 0 & 0 \\
\hline Targeted Trading & 0 & 0 & 0 & 0 & 0 & 0 & 0 & 0 & 0 & 1 \\
\hline
\end{tabular}

Abbreviations: AML, anti-money laundering; ANX, ANXBTC; BitK, BitKonan; BitS, BitStamp;KYC, know-your-customer; Local, LocalBitcoin; LOOP, relative law of one price; Rock, The Rock Trading.

The two exchanges that Consistently Fail LOOP share seven characteristics: neither disclose their server location; they are not located in the USA; they allow funding of accounts and withdrawal of BTC without 
ID; neither have an extreme trade share (either high or approximately zero share of global transactions); neither have a statement banning off-chain transactions; and neither have a debit card available. Of these seven characteristics, six are found in at least one of the LOOP exchanges - server location (Kraken), USA location (ANXBTC), no extreme high/low volume (ANXBTC, Kraken), off-chaining (all), and debit card (itBit, Kraken) - so it seems unlikely that these characteristics can explain why LOOP fails. ${ }^{26}$ This leaves only the KYC implementation variables: all exchanges with LOOP require ID's to Fund the account, a requirement that neither HitBTC nor LocalBitcoin enforce.

The exchanges that exhibit Inconsistent LOOP Failure (Weak or Strong) also do not require identification information to fund the account, so we interpret a failure to require an ID to fund as predictive of LOOP failure. There is no characteristic that distinguishes exchanges with Consistent LOOP Failure from those that have Inconsistent LOOP Failure. Inconsistent LOOP exchanges differ from each other on acceptance of Euro trades, yet it seems unlikely that these are a distinguishing feature as both LOOP and Failed LOOP exchanges allow Euro trades. This implies that there are additional, potentially hidden, exchange characteristics not captured on Table 8 that explain the degree of LOOP failure.

\subsection{Price Deviation and Exchange Characteristics}

We define the price deviation of an exchange as the difference between a given price-series and the corresponding price-series for the reference exchange (BitFinex):

$$
\text { Deviation }_{t}^{i}=\log \left(\left|\frac{p_{t}^{i}}{p_{t}^{\text {BitFinex }}}-1\right|\right)
$$

For some series, like the High price-series, a deviating price is typically greater than the reference series $\left(\frac{p_{t}^{i}}{p_{t}^{\text {BitFinex }}}>1\right)$ so a positive coefficient would indicate more deviation, while for others, like the Low price series, deviating prices are typically less than the reference series $\left(\frac{p_{t}^{i}}{p_{t}^{B i t F i n e x}}<1\right)$ and a negative coefficient indicates more deviation. By using the absolute value of the deviation from parity in equation 5 , a positive coefficient can consistently be interpreted as greater price deviation from the reference series. ${ }^{27}$ We also calculate the daily Trade Volume $\left(T V R_{t}^{i}\right)$ for each exchange, normalized by the daily BitFinex volume to account for a growth in bitcoin trading over the sample

$$
T V R_{t}^{i}=\frac{V o l_{t}^{i}}{V o l_{t}^{\text {BitFinex }}}
$$

\footnotetext{
${ }^{26}$ It is important to recall that we only selected exchanges reporting 410 days or more with transactions; the finding regarding trade volume can therefore more accurately be considered as suggesting that active exchanges follow long-run price trends regardless of size.

${ }^{27}$ The $\log$ is applied to normalize the distribution.
} 
Table 9: Mean and Standard Deviation of Price Deviation and Normalized Trade Volume

\begin{tabular}{|l|cccc|cc|cc|cc||c||c|}
\hline & \multicolumn{4}{|c|}{ No LOOP Failure } & \multicolumn{2}{|c|}{ Weak LOOP Failure } & \multicolumn{2}{c|}{ Strong LOOP Failure } & \multicolumn{2}{c|}{ LOOP Failure } \\
& ANX & BitS & itBit & Kraken & Lake & BitK & BTC-e & Rock & Local & HitBTC & Aggregate \\
\hline Open & -5.47 & -6.08 & -5.70 & -4.85 & -5.41 & -4.35 & -4.59 & -4.51 & -2.02 & -4.05 & -4.70 \\
& $(1.38)$ & $(1.26)$ & $(1.18)$ & $(1.36)$ & $(1.05)$ & $(1.06)$ & $(0.93)$ & $(1.12)$ & $(1.17)$ & $(1.64)$ & $(1.64)$ \\
Close & -5.32 & -6.07 & -5.72 & -4.77 & -5.39 & -4.09 & -4.64 & -4.61 & -2.09 & -3.99 & -4.67 \\
& $(1.31)$ & $(1.27)$ & $(1.20)$ & $(1.25)$ & $(1.00)$ & $(1.11)$ & $(1.00)$ & $(1.17)$ & $(1.14)$ & $(1.59)$ & $(1.62)$ \\
Weighted & -5.08 & -6.00 & -5.44 & -5.02 & -5.39 & -4.23 & -4.60 & -4.56 & -2.24 & -4.01 & -4.65 \\
& $(1.22)$ & $(1.20)$ & $(1.20)$ & $(1.36)$ & $(1.07)$ & $(1.17)$ & $(0.93)$ & $(1.07)$ & $(0.28)$ & $(1.59)$ & $(1.52)$ \\
High & -4.99 & -5.77 & -5.23 & -4.79 & -5.32 & -4.09 & -4.50 & -4.14 & 0.78 & -4.10 & -4.21 \\
& $(1.31)$ & $(1.24)$ & $(1.04)$ & $(1.24)$ & $(1.08)$ & $(1.31)$ & $(0.87)$ & $(1.28)$ & $(0.65)$ & $(1.77)$ & $(2.13)$ \\
Low & -4.88 & -5.75 & -5.52 & -4.92 & -5.17 & -4.16 & -4.64 & -4.71 & -2.06 & -3.93 & -4.57 \\
& $(1.44)$ & $(1.27)$ & $(1.36)$ & $(1.26)$ & $(1.05)$ & $(1.19)$ & $(1.06)$ & $(1.34)$ & $(0.50)$ & $(1.52)$ & $(1.58)$ \\
\hline TVR & 0.08 & 0.63 & 0.16 & 0.00 & 0.30 & 0.00 & 0.41 & 0.00 & 0.10 & 0.04 & 0.17 \\
& $(0.10)$ & $(0.38)$ & $(0.17)$ & $(0.00)$ & $(0.27)$ & $(0.00)$ & $(0.24)$ & $(0.00)$ & $(0.09)$ & $(0.06)$ & $(0.27)$ \\
\hline
\end{tabular}

The mean and standard deviation for each price-series and exchange are summarized in Table 9. Price deviations for exchanges that achieve LOOP are below average, while exchanges with Consistent LOOP Failure have more deviations than the average. Daily trade volume varies over the four categories, with the exchanges that have a negligible share of global bitcoin trade (Kraken, BitKonan, and Rock) also have a negligible share of trade relative to BitFinex.

The relationship between LOOP failure and the magnitude of price deviations is evaluated using an an OLS regression with robust standard error. Table 10 reports the coefficients. ${ }^{28}$ Prices from the BPI are removed as it is an index constructed using prices from exchanges in this sample, not an exchange. BitFinex is removed as it is the reference series. Date fixed effects are included.

Table 10: Price Deviation and LOOP Results

\begin{tabular}{|c|c|c|c|c|c|c|c|c|c|c|}
\hline & \multicolumn{5}{|c|}{ LocalBitcoins Included } & \multicolumn{5}{|c|}{ LocalBitcoins Removed } \\
\hline & Open & Close & Weighted & High & Low & Open & Close & Weighted & High & Low \\
\hline Weak LOOP Failure & $0.65^{* * *}$ & $0.74^{* * *}$ & $0.58^{* * *}$ & $0.49^{* * *}$ & $0.61^{* * *}$ & $0.65^{* * *}$ & $0.74^{* * *}$ & $0.58^{* * *}$ & $0.49^{* * *}$ & $0.61^{* * *}$ \\
\hline Strong LOOP failure & $0.98^{* * *}$ & $0.84^{* * *}$ & $0.80^{* * *}$ & $0.87^{* * *}$ & $0.59^{* * *}$ & $0.98^{* * *}$ & $0.84^{* * *}$ & $0.80^{* * *}$ & $0.87^{* * *}$ & $0.59^{* * *}$ \\
\hline Consistent LOOP Failure & $2.49^{* * *}$ & $2.43^{* * *}$ & $2.26^{* * *}$ & $3.53^{* * *}$ & $2.27^{* * *}$ & $1.48^{* * *}$ & $1.48^{* * *}$ & $1.37^{* * *}$ & $1.09^{* * *}$ & $1.33^{* * *}$ \\
\hline Constant & $-5.53^{* * *}$ & $-5.47 * * *$ & $-5.38^{* * *}$ & $-5.19 * * *$ & $-5.27^{* * *}$ & $-5.53^{* * *}$ & $-5.47^{* * *}$ & $-5.38^{* * *}$ & $-5.19^{* * *}$ & $-5.27^{* * *}$ \\
\hline Date fixed effect? & $\mathrm{Y}$ & $\mathrm{Y}$ & $\mathrm{Y}$ & Y & Y & $\mathrm{Y}$ & Y & Y & $\mathrm{Y}$ & $\mathrm{Y}$ \\
\hline Adj. $R^{2}$ & 0.30 & 0.30 & 0.31 & 0.36 & 0.30 & 0.14 & 0.14 & 0.14 & 0.10 & 0.14 \\
\hline $\mathrm{N}$ & 4243 & 4243 & 4238 & 4241 & 4233 & 3817 & 3818 & 3812 & 3815 & 3807 \\
\hline
\end{tabular}

Two observations can be made from Table 10: The positive coefficients on all three dummy variables show that LOOP failure is associated with larger price deviations. Secondly, the magnitude of price deviations and the severity of LOOP failure are positively associated for all price-series except the Low prices. For the Low price-series the magnitude of deviations associated with Weak LOOP Failure is slightly larger than Strong LOOP Failure. Table 2 showed that LocalBitcoins prices are more volatile than other exchanges; excluding

\footnotetext{
${ }^{28}$ The regression is Deviation ${ }_{t}^{i}=\beta^{1}$ Weak LOOP Failure $+\beta^{2}$ Stong LOOP failure $+\beta^{3}$ Consistent LOOP failure + constant
} 
it from the regression does not change the findings, though it does reduce the magnitude of deviations associated with Consistent LOOP failure. Even with this reduction, the magnitude of price deviations on exchanges that Consistently Fail LOOP are twice as large as the magnitude of deviations for exchanges that have Weak LOOP Failure. Understanding which of the 22 exchange characteristics (summarized in Table 8) contribute toward price deviations can therefore help us identify characteristics associated with LOOP failure.

Table 11 reports the results from an OLS regression of price deviation and exchange characteristics with robust standard errors, ${ }^{29}$

$$
\text { Deviation }_{t}=\alpha+\sum_{k} \beta^{k} I^{k}+\beta^{V} T V R_{t}^{i}+\sum_{t} \beta_{t} F E_{t}+\epsilon
$$

where $I^{k}$ are the exchange characteristics indicated in Table 8 , as well as their interactions, and $F E_{t}$ is a date fixed effect.

Four of the 22 potential characteristics act as fixed effects for specific exchanges and are not considered: A Stated AML/KYC policy, Free Bitcoin Deposit, and Targeted Trading all act as fixed effects for LocalBitcoin, while Not Allowing Off-chaining is a fixed effect for Kraken. An additional six - Known Incorporation, Known Physical Address, High Volume Trade, Inclusion in the BPI, Hacked, and Debt Card Available differ for only two exchanges, and frequently cause multicollinearity issues if included. Two more, Free Fiat Deposits and ID For Currency Withdrawals, are problematic as they cannot be evaluated for LocalBitcoins which does not allow fiat currency deposits. Finally, the values for "ID for BTC withdrawals" duplicates the values of "ID for Funding". This leaves nine of the original 22 characteristics for consideration.

Results in section 5.2 showed that requiring an ID to fund an account is an important characteristic in explaining LOOP failure, and therefore "ID to Fund" must be included. Indicator variables for Knowledge of Server Location, USA Location, Trades in Euros, GBP, and Trades in Other Currencies all result in a variance-inflation factor above 3, indicating multicollinearity when included with ID to Fund, so they are removed. This leaves 4 characteristics for consideration with price deviation: ID for Funding, Fixed Trading Fee, Free Trades Feasible, and Low Global Share of bitcoin trade volume.

The basic regression, (i), for each price-series considers only the impact that requiring an ID to Fund has on price deviations. Regression (ii) uses the remaining characteristics, trade volume, and their interactions if they do not result in multicollinearity. All statistically significant variables have consistent signs across all price-series, confirming results from Section 4.2 that the effects documented in this paper are not isolated to a single price series.

\footnotetext{
${ }^{29}$ Allowing for lags with Newey West Errors does not change results.
} 
Table 11: Price Deviation and Exchange Characteristics

\begin{tabular}{|c|c|c|c|c|c|c|c|c|c|c|}
\hline & \multicolumn{2}{|c|}{ Open } & \multicolumn{2}{|c|}{ Close } & \multicolumn{2}{|c|}{ Weighted } & \multicolumn{2}{|c|}{ High } & \multicolumn{2}{|c|}{ Low } \\
\hline & (i) & (ii) & (i) & (ii) & (i) & (ii) & (i) & (ii) & (i) & (ii) \\
\hline ID to Fund & $-1.38^{* * *}$ & $-1.92^{* * *}$ & $-1.34^{* * *}$ & $-1.79 * * *$ & $-1.22^{* * *}$ & $-1.53^{* * *}$ & $-1.64^{* * *}$ & $-2.27 * * *$ & $-1.16^{* * *}$ & $-1.53^{* * *}$ \\
\hline ID to Fund $x$ Low Share & & $1.50^{* * *}$ & & $1.50^{* * *}$ & & $0.98^{* * *}$ & & $1.25^{* * *}$ & & $1.18^{* * *}$ \\
\hline Low Global Share & & $-0.40^{* * *}$ & & $-0.23^{* *}$ & & $-0.32^{* * *}$ & & $-0.57 * * *$ & & $-0.32 * * *$ \\
\hline Fixed Cost to Trade & & $-0.12^{*}$ & & 0.05 & & 0.01 & & $-0.83^{* * *}$ & & 0.09 \\
\hline Free Trade Feasible & & $0.83^{* * *}$ & & $0.82^{* * *}$ & & $0.78^{* * *}$ & & $1.86^{* * *}$ & & $0.99^{* * *}$ \\
\hline Trade Volume & & $-0.33^{* * *}$ & & $-0.39 * * *$ & & $-0.58^{* * *}$ & & $-0.74^{* * *}$ & & $-0.33^{* *}$ \\
\hline Volume x Low Share & & $-167.55^{* * *}$ & & $-248.08 * * *$ & & $-159.61 * * *$ & & $-160.24^{* * *}$ & & $-227.45^{* * *}$ \\
\hline Volume x Fixed Cost & & $-1.02^{* * *}$ & & $-1.07 * * *$ & & $-0.73^{* * *}$ & & $-0.74^{* * *}$ & & $-1.07 * * *$ \\
\hline Volume x Free Trade & & $-3.06^{* * *}$ & & $-2.56^{* * *}$ & & $-2.47^{* * *}$ & & $-5.07 * * *$ & & $-2.72^{* * *}$ \\
\hline Constant & $-4.15^{* * *}$ & $-3.87^{* * *}$ & $-4.13^{* * *}$ & $-3.99 * * *$ & $-4.17^{* * *}$ & $-3.99^{* * *}$ & $-3.55 * * *$ & $-3.03^{* * *}$ & $-4.10 * * *$ & $-4.01 * * *$ \\
\hline Date fixed effect? & $\mathrm{Y}$ & $\mathrm{Y}$ & $\mathrm{Y}$ & $\mathrm{Y}$ & $\mathrm{Y}$ & $\mathrm{Y}$ & $\mathrm{Y}$ & $\mathrm{Y}$ & $\mathrm{Y}$ & $\mathrm{Y}$ \\
\hline Adj. $R^{2}$ & 0.15 & 0.25 & 0.15 & 0.25 & 0.15 & 0.24 & 0.09 & 0.30 & 0.13 & 0.24 \\
\hline $\mathrm{N}$ & 4243 & 4243 & 4243 & 4243 & 4238 & 4238 & 4241 & 4241 & 4233 & 4233 \\
\hline
\end{tabular}

Exchanges that require ID to Fund have smaller price deviations those than those that do not, though the effect is diminished for exchanges with a low global share of bitcoin trades. Having a larger trade volume is also associated with smaller deviations, an effect that is especially potent for the small exchanges. ${ }^{30}$ Exchanges where free trade is feasible - usually as a result of trading large volumes — see larger price deviations, although this is mitigated in exchanges with larger trade volumes. It is worth noting this suggests that fees on bitcoin exchanges are substantial enough to impact prices.

Of the characteristics considered above, requiring an ID to Fund an account have largest impact on decreasing price deviations. This is consistent with findings that showed ID to be a good indicator of LOOP.

\section{Conclusions}

Crypto-currencies like Bitcoin are a comparatively new financial mechanism, and are not yet assimilated into a consistent global regulatory framework. Of the 11 bitcoin exchanges we evaluate, we find that exchanges which do not fully implement AML and/or KYC-two regulatory policies already in broad use across the global financial system - exhibit statistically different price patterns from exchanges that do. This suggests two things. First, standard financial regulations can affect bitcoin markets, even across a group of different global exchanges. Second, bitcoin-pricing data can differ across exchanges, not obeying the Law of One Price, in ways that are not always obvious, demanding a deliberate approach to data sourcing.

It may seem strange that requiring an ID to fund an account should matter to bitcoin users. Although bitcoin transactions are more private than cash transactions they are actually less anonymous. Every bitcoin wallet is identified by a unique "private key". The private keys of both wallets in a bitcoin transaction are

\footnotetext{
${ }^{30}$ Recall that "Low Global Share" was defined as an exchange that traded approximately $0 \%$ of global bitcoin trades, so a coefficient of -167.55 has a substantially smaller impact than it appears.
} 
recorded on the "blockchain". The blockchain can be thought of as a digital ledger, maintaining a history of bitcoin transactions. Anonymity results only if it is impossible to prove a connection between the private key and an individual. ${ }^{31}$ There is some evidence that users with criminal intentions use bitcoin: using Google search data, Wilson and Yelowitz (2015) find evidence of significant criminal interest in bitcoin. For these users, the anonymity promised by using bitcoin is its primary benefit, a benefit which is eliminated (or substantially undermined) by exchanges which require ID.

\section{References}

Akram, Q. F., Rime, D., Sarno, L., December 2008. Arbitrage in the Foreign Exchange Market: Turning on the Microscope. Journal of International Economics 76 (2), 237-253.

Ali, R., Barrdear, J., Clews, R., Southgate, J., Q3 2014. The economics of digital currencies. Bank of England Quarterly Bulletin.

Badev, A., Chen, M., 2014. Bitcoin: Technical background and data analysis. FRB Finance and Economics Discussion Series 104.

Böhme, R., Christin, N., Edelman, B., Moore, T., Spring 2015. Bitcoin: Economics, technology, and governance. Journal of Economic Perspectives.

Brandvold, M., Molnár, P., Vagstad, K., Valstad, O. C. A., May 2015. Price discovery on bitcoin exchanges. Journal of International Financial Markets, Institutions and Money 36, 18-35.

Brière, M., Oosterlinck, K., Szafarz, A., 2015. Virtual currency, tangible return: Portfolio diversification with bitcoins. Journal of Asset Management.

Chu, J., Nadarajah, S., Chan, S., July 2015. Statistical analysis of the exchange rate of bitcoin. PLOS ONE $10(7)$.

Ciaian, P., Rajcaniova, M., dArtis Kancs, 2016. The economics of BitCoin price formation. Applied Economics 48 (19), 1799-1815.

Dickey, D. A., Fuller, W. A., 1979. Distribution of the estimators for autoregressive time series with a unit root. Journal of the American Statistical Association 74, 427-431.

Dwyer, G. P., April 2015. The economics of Bitcoin and similar private digital economies. Journal of Financial Stability, 81-91.

\footnotetext{
${ }^{31}$ For a discussion of the technology involved, refer to Badev and Chen (2014) or Böhme et al. (2015).
} 
Elliot, G., Rothenberg, T., Stock, J., 1996. Efficient tests for an autoregressive unit root. Econometrica 64, $813-836$.

Eun, C. S., Sabherwal, S., April 2003. Cross-Border Listings and Price Discovery: Evidence from U.S.-Listed Canadian Stocks. The Journal of Finance 58 (2).

Glaser, F., Zimmermann, K., Haferkorn, M., Weber, M. C., Siering, M., 9-14 June 2014. Bitcoin-asset or currency? Revealing users' hidden intentions. Twenty-Second European Conference on Information Systems (ECIS), Tel Aviv.

Greene, C., Shy, O., September 2014. E-cash and virtual currency as alternative payment methods. Journal of Payments Strategy and Systems 8 (3).

Greene, W. H., 2007. Econometric Analysis. Pearson Eduction.

Halaburda, H., Gandal, N., October 2014. Competition in the cryptocurrency market. NET Institute Working Paper No. 14-17Available at SSRN, http://dx.doi.org/10.2139/ssrn.2506463.

Johansen, S., 1995. Likelihood-Based Inference in Cointegrated Vector Autoregressive Models. Oxford University Press.

Kaplanov, N. M., 2012. Nerdy Money: Bitcoin, the Private Digital Currency, and the Case Against its Regulation. Loyola Consumer Law Review 25 (1).

King, D., February 2016. Banking Bitcoin-Related Businesses: A Primer for Managing BSA/AML Risks. Retail Payments Risk Forum Working Paper - Federal Reserve Bank of Atlanta.

Kristoufek, L., 2013. Bitcoin meets Google Trends and Wikipedia: Quantifying the relationship between phenomena of the Internet era. Scientific Reports 3, article no. 3415.

Kroll, J., Davey, I. C., Felten, E. W., June 2013. The economics of bitcoin mining, or bitcoin in the presence of adversaries. The Twelfth Workshop on the Economics of Information Security (WEIS 2013), Washington.

Kwiatkowski, P. D., Phillips, P., Schmidt, P., Shin, Y., 1992. Testing the null hypothesis of stationarity against the alternative of a unit root: How sure are we that economic time series have a unit root? Journal of Econometrics 54, 159-178.

Lo, S., Wang, J. C., September 2014. Bitcoin as money? Federal Reserve Bank of Boston: Current Policy Perspectives 14-4. 
Luther, W., 2016. Cryptocurrencies, Network Effects, and Switching Costs. Contemporary Economic Policy $34(3)$.

Nakamoto, S., 2008. Bitcoin: A peer-to-peer electronic cash systemAvailable at http://bitcoin.org/bitcoin.pdf.

Parkinson, M., 1980. The extreme value method of estimating the variance of the rate of return. Journal of Business 53 .

Pesaran, M., Shin, Y., Smith, R., 2001. Bounds testing approaches to the analysis of level relationships. Journal of Applied Econometrics 16, 289-326.

Rogers, L., Satchell, S., 1991. Estimating variance from high, low, and closing prices. Annals of Applied Probability.

Toda, H., Yamamoto, T., 1995. Statistical inferences in vector autoregressions with possibly integrated processes. Journal of Econometrics 66, 225-250.

Urquhrat, A., November 2016. The inefficiency of Bitcoin. Economics Letters 148, 80-82.

Velde, F. R., December 2013. Bitcoin: A primer. Chicago Fed Letter (317).

White, L., 2015. The Market for Cyryptocurrencies. Cato Journal 35 (2).

Wilson, M., Yelowitz, A., September 2015. Characteristics of Bitcoin users: An analysis of Google search data. Applied Economics Letters 22, 1030-1036.

Yermack, D., 2015. Is Bitcoin a real currency? An economic appraisal. In: Chuen, D. L. K. (Ed.), Handbook of Digital Currency. Elsevier, pp. 31-44. 


\section{Appendices}

\section{A Implications for bitcoin research}

\section{A.1 Are differences in bitcoin exchange prices sufficient to impact research?}

The failure of some exchanges to achieve LOOP has important ramifications for those studying bitcoin. By design, there is no central "official" source for bitcoin prices. Studies prior to February 2014 used the bitcoin marketplace "Mt. Gox" for price information, as it handled approximately $70 \%$ of the global bitcoin trade. Mt. Gox, however, declared bankruptcy in February 2014, and the largest exchange during the period we study (BitFinex) handles only $11 \%$ of bitcoin transactions. As the sample of published bitcoin papers in Table 12 illustrates, researchers currently use prices from any source that suits the purpose of their study—or use prices from a bitcoin index - under the assumption that their results generalize across all bitcoin markets.

Table 12: Sources of Bitcoin Price Information for papers after the collapse of Mt. Gox

\begin{tabular}{|l|c|c|c|c|c|c|}
\hline \multicolumn{1}{|c|}{ Author } & Bitstamp & BTC-e & BitFinex & BTC China & Quandl/BPI/Index & OKCoin \\
\hline Badev and Chen (2014) & $\mathrm{X}$ & $\mathrm{X}$ & $\mathrm{X}$ & $\mathrm{X}$ & & $\mathrm{X}$ \\
Ciaian, Rajcaniova, and dArtis Kancs (2016) & & & & & \\
Chu, Nadarajah, and Chan (2015) & $\mathrm{X}$ & & & & \\
Lo and Wang (2014) & $\mathrm{X}$ & & & & $\mathrm{X}$ & \\
Urquhrat (2016) & & & & & \\
\hline
\end{tabular}

Might different research results be achieved by using a price-series from a different exchange? To investigate the extent of possible distortions we examine bitcoin volatility, a transparent statistic, to see if there are substantial differences across exchanges and price-series. Table 13 lists the median volatility of a 30-day rolling window of bitcoin prices, with exchanges grouped by adherence to LOOP. There are three different measures of volatility employed for each market: the standard-deviation-based volatility based on a single price-series, $\sigma^{S D, x}$; the Parkinson (1980) volatility, $\sigma^{H L}$, based on High and Low prices; and the Rogers and Satchell (1991) volatility, $\sigma^{O H L C}$ which uses Open, High, Low, and Close prices.

$$
\begin{aligned}
\sigma^{S D, x} & =\frac{\sqrt{\frac{1}{T}} \sqrt{\sum_{t=1}^{T}\left(p_{t}^{x}-\bar{p}^{x}\right)^{2}}}{\bar{p}^{x}} \\
\sigma^{H L} & =\frac{\sqrt{\frac{1}{T}} \sqrt{\frac{1}{4 \ln 2} \sum_{t=1}^{T}\left(p_{t}^{H}-p_{t}^{L}\right)^{2}}}{\frac{1}{2}\left(\bar{p}^{H}+\bar{p}^{L}\right)} \\
\sigma^{O H L C} & =\frac{\sqrt{\frac{1}{T}} \sqrt{\sum_{t=1}^{N}\left(p_{t}^{H}-p_{t}^{C}\right)\left(p_{t}^{H}-p_{t}^{O}\right)+\left(p_{t}^{L}-p_{t}^{C}\right)\left(p_{t}^{L}-p_{t}^{O}\right)}}{\frac{1}{4}\left(\bar{p}^{O}+\bar{p}^{H}+\bar{p}^{L}+\bar{p}^{C}\right)}
\end{aligned}
$$


Table 13: Median 30-Day Price Volatility (\%)

\begin{tabular}{|c|c|c|c|c|c|c|c|}
\hline & \multicolumn{5}{|c|}{$\sigma^{S D, x}$} & \multirow[b]{2}{*}{$\sigma^{H L}$} & \multirow[b]{2}{*}{$\sigma^{O H L C}$} \\
\hline & Open & Close & Weighted & Low & High & & \\
\hline \multicolumn{8}{|l|}{ LOOP Exchanges } \\
\hline ANXBTC & 6.32 & 6.39 & 6.28 & 6.83 & 6.38 & 4.76 & 5.60 \\
\hline BitFinex & 6.37 & 6.37 & 6.32 & 6.60 & 6.29 & 3.49 & 3.64 \\
\hline BitStamp & 6.33 & 6.34 & 6.27 & 6.61 & 6.18 & 3.43 & 3.52 \\
\hline BPI & 6.40 & 6.40 & - & 6.60 & 6.27 & 3.11 & 3.07 \\
\hline itBit & 6.27 & 6.29 & 6.24 & 6.45 & 6.16 & 3.00 & 3.85 \\
\hline Kraken & 6.40 & 6.45 & 6.32 & 6.61 & 6.27 & 3.79 & 4.09 \\
\hline LOOP Average & 6.35 & 6.37 & 6.29 & 6.62 & 6.26 & 3.60 & 3.96 \\
\hline \multicolumn{8}{|c|}{ Weakly LOOP Failure Exchanges } \\
\hline LakeBTC & 6.27 & 6.28 & 6.17 & 6.42 & 6.18 & 3.25 & 3.27 \\
\hline BitKonan & $6.32^{*}$ & 6.93 & 6.49 & 7.08 & 6.98 & 5.30 & $6.37^{*}$ \\
\hline \multicolumn{8}{|c|}{ Strong LOOP Failure Exchanges } \\
\hline BTC-e & 6.22 & 6.28 & 6.13 & 6.38 & 6.14 & 3.42 & 3.57 \\
\hline The Rock Trading & 6.22 & 6.38 & 5.99 & $6.27^{*}$ & 6.51 & $4.78^{*}$ & $5.84^{*}$ \\
\hline \multicolumn{8}{|c|}{ Consistent LOOP Failure Exchanges } \\
\hline HitBTC & 6.08 & 6.09 & 5.87 & 6.20 & 6.09 & 3.56 & 3.85 \\
\hline LocalBitcoins & 20.37 & 19.08 & $5.97^{*}$ & 10.32 & 39.32 & 86.34 & 173.77 \\
\hline
\end{tabular}

Where $x$ indicates the Open (O), High (H), Low (L), or Close (C) price respectively, $\bar{p}^{x}$ indicates the average price, and exchange specific indexes are suppressed. To make the measures comparable across each exchange and price series, each $\sigma$ is normalized using the mean of the daily price for the period (or averaged price if multiple price series are used). Over the same time period, the equivalent standard deviation-based volatility of the price of gold is $1.8 \%$, the USD-EUR exchange rate is $1.4 \%$, and the S\&P 500 is $1.3 \% .{ }^{32}$

The data in Table 13 confirm that bitcoin is more volatile than gold, exchange rate, and stock market prices, regardless of the exchange or price-series - how much more volatile bitcoin is depends on the data used. The volatility on LocalBitcoins is magnitudes larger than other exchanges for all price-series except transaction-weighted prices. HitBTC yields the opposite: it usually has the lowest volatility. These results show that using data from an exchange that fails to yield LOOP can impact empirical conclusions, but that it is difficult to precisely predict the effect: The volatility of LocalBitcoin is consistently greater than that of LOOP series, while the volatility of HitBTC is almost always below average. The exchanges that failed to yield LOOP in the robustness checks are less consistent in their deviations from LOOP average than HitBTC and LocalBitcoins.

Volatility varies even among LOOP exchanges. Volatility estimates using standard deviations vary from

\footnotetext{
${ }^{32}$ We obtain the daily 10 a.m. Gold Fixing Price in London Bullion Market in USD, the USD-EUR exchange rate, and the S\&P 500 Index from the Federal Reserve Economic Database (FRED) of the St. Louis Federal Reserve Bank for the time period of the bitcoin sample.
} 
$6.16 \%$ to $6.83 \%$ (a range of 0.67 percentage points). Estimates that combine different price-series, $\sigma^{H L}$ and $\sigma^{O H L C}$, vary even more. Parkinson volatility ranges from $3.00 \%$ to $4.76 \%$ (a 1.76 percentage point spread) while the Rogers-Satchell volatility ranges from $3.07 \%$ to $5.60 \%$ (a 2.53 percentage point spread). Volatility across bitcoin markets are highly dependent upon which exchange, price-series, and measure is used.

\section{A.2 Correlations}

Bitcoin prices are non-stationary, which biases correlation results. Despite this, some studies have drawn their conclusions from only correlations. We repeat our analysis from section 4 but examine only the correlations of the twelve exchanges to BitFinex (the largest exchange), with results presented in Table 14.

Table 14: Correlation Characteristics Across Exchanges

\begin{tabular}{|l|lllll|lllll|}
\hline & ANX & BitK & BitS & BTC-e & HitB & itBi & Krak & Lake & Local & Rock \\
\hline Open & 1.00 & 1.00 & 1.00 & 1.00 & 1.00 & 1.00 & 1.00 & 1.00 & 0.87 & 1.00 \\
Close & 1.00 & 1.00 & 1.00 & 1.00 & 1.00 & 1.00 & 1.00 & 1.00 & 0.89 & 1.00 \\
Weighted & 1.00 & 1.00 & 1.00 & 1.00 & 1.00 & 1.00 & 1.00 & 1.00 & 1.00 & 1.00 \\
Low & 1.00 & 0.99 & 1.00 & 1.00 & 1.00 & 0.98 & 1.00 & 1.00 & 0.97 & 1.00 \\
High & 1.00 & 0.99 & 1.00 & 1.00 & 1.00 & 1.00 & 1.00 & 1.00 & 0.14 & 0.99 \\
\hline
\end{tabular}

The correlation results are similar regardless of which reference series is used and are typically close to one, implying (incorrectly) that all series are interchangeable. Possible exceptions exist only for some LocalBitcoins price-series. This contradiction of the cointegration results in section 4.2 should give pause when basing interpretations on correlation results alone. 


\section{B Online Appendix: Additional Figures and Robustnesss Checks}

\section{B.1 Prices Levels}

Figures (3) - (7) plot all price series for all exchanges. The two vertical lines denote the end of the first segment and beginning of the second segment used for the structural break test in section 4.3.2. All price series for all exchanges are still descending at the end of the first segment; all have plateaued by the beginning of the second segment. The volatility of the Transaction Weighted price series for LocalBitcoins in Figure 5 is noticeably lower than it is for the other four price series.

Figure 3: Open Prices
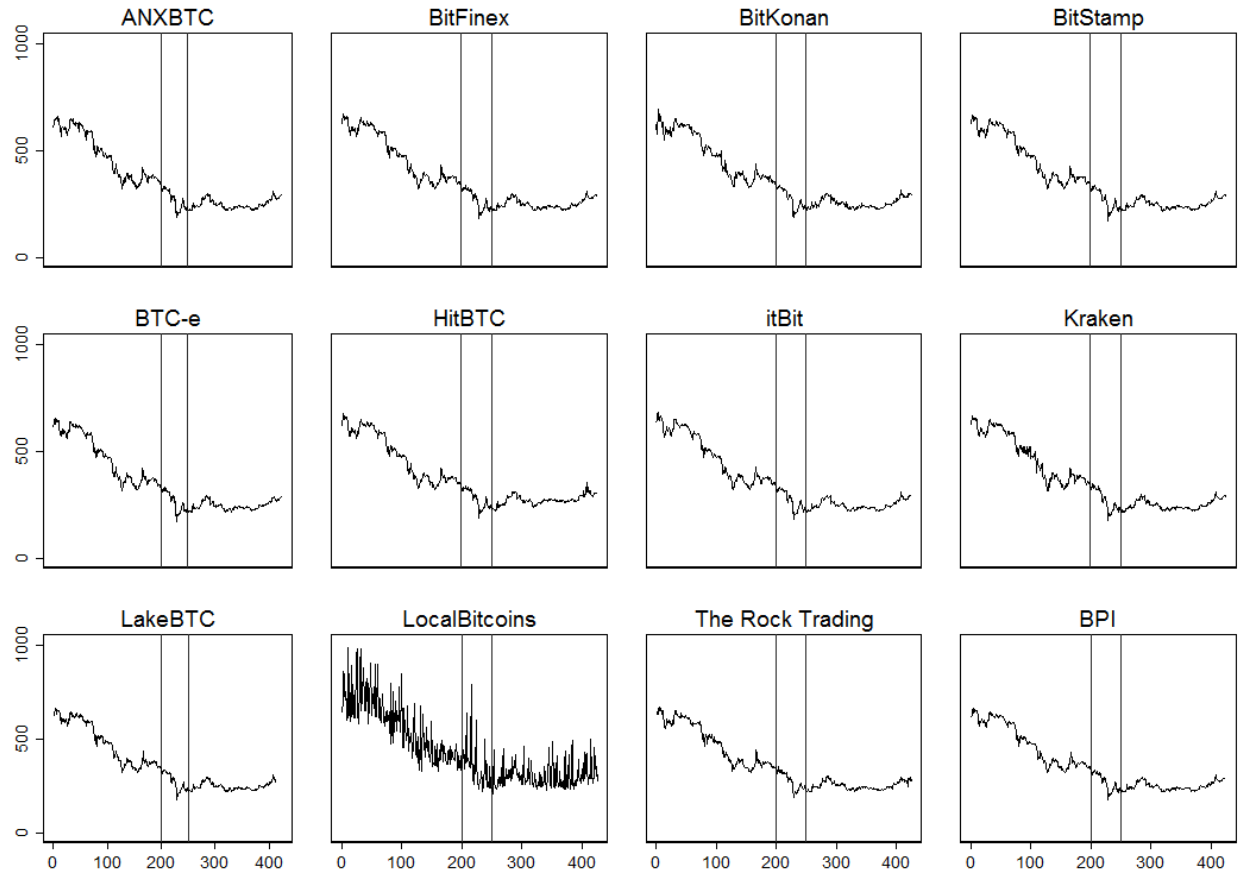
Figure 4: Close Prices

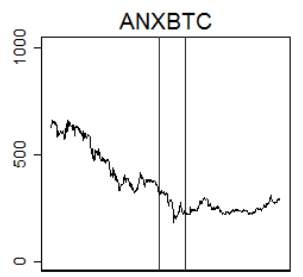

BitFinex
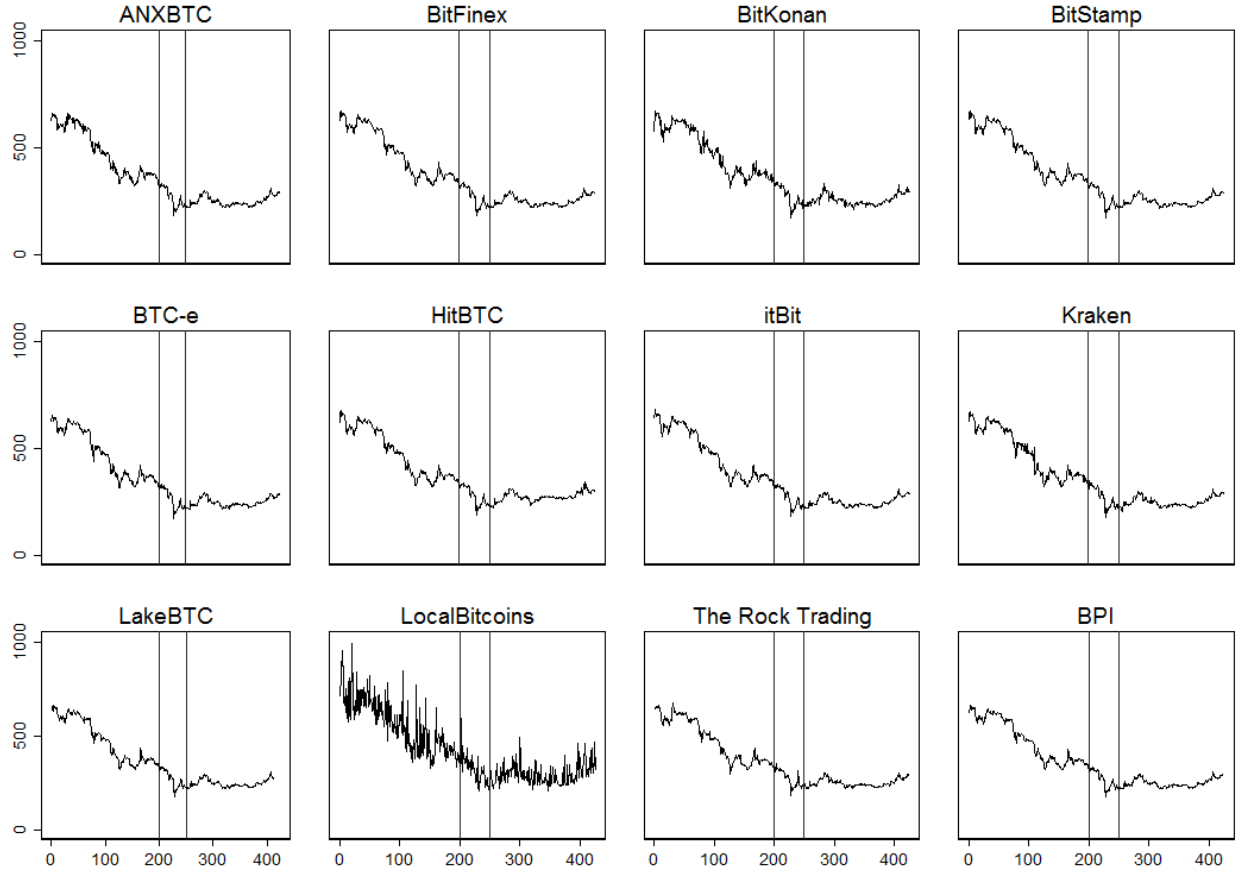

Figure 5: Weighted Prices
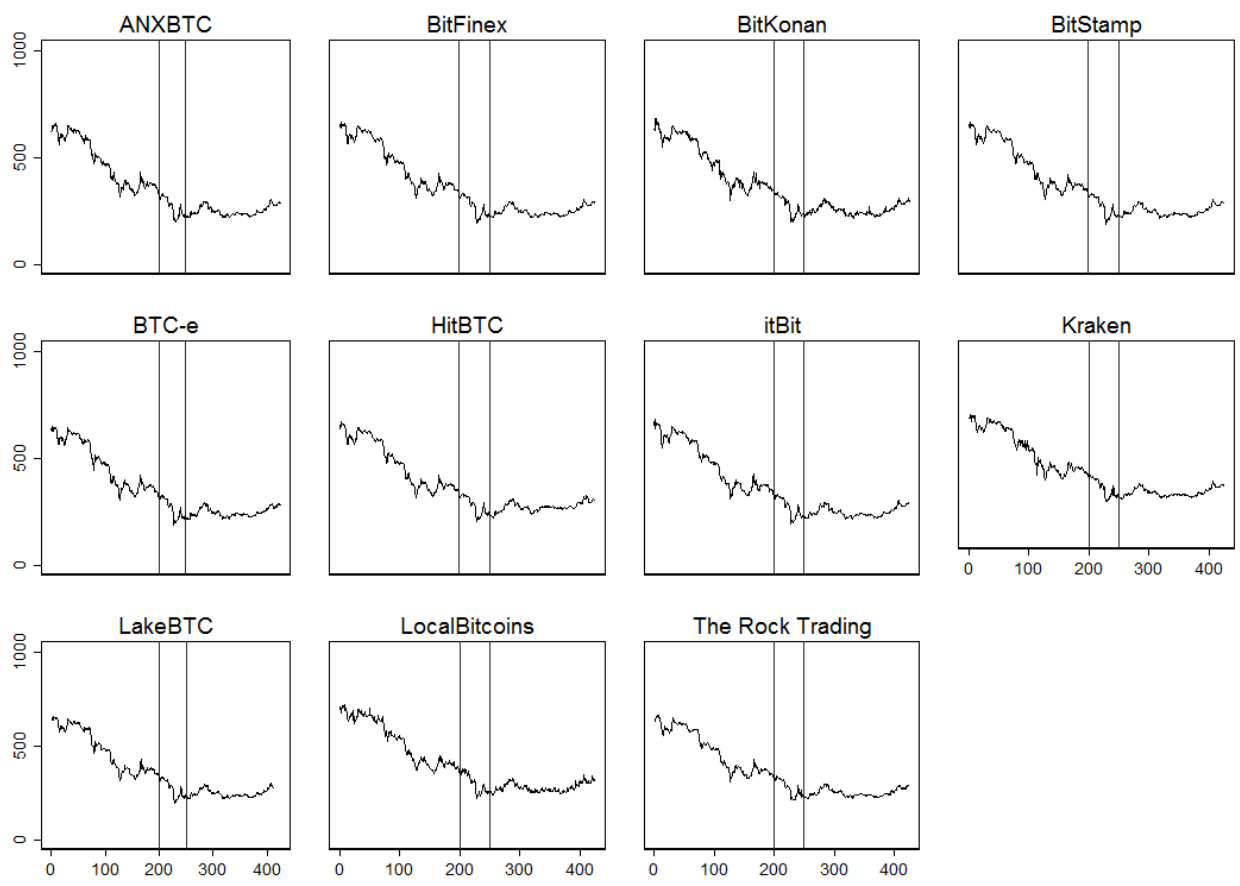
Figure 6: Low Prices
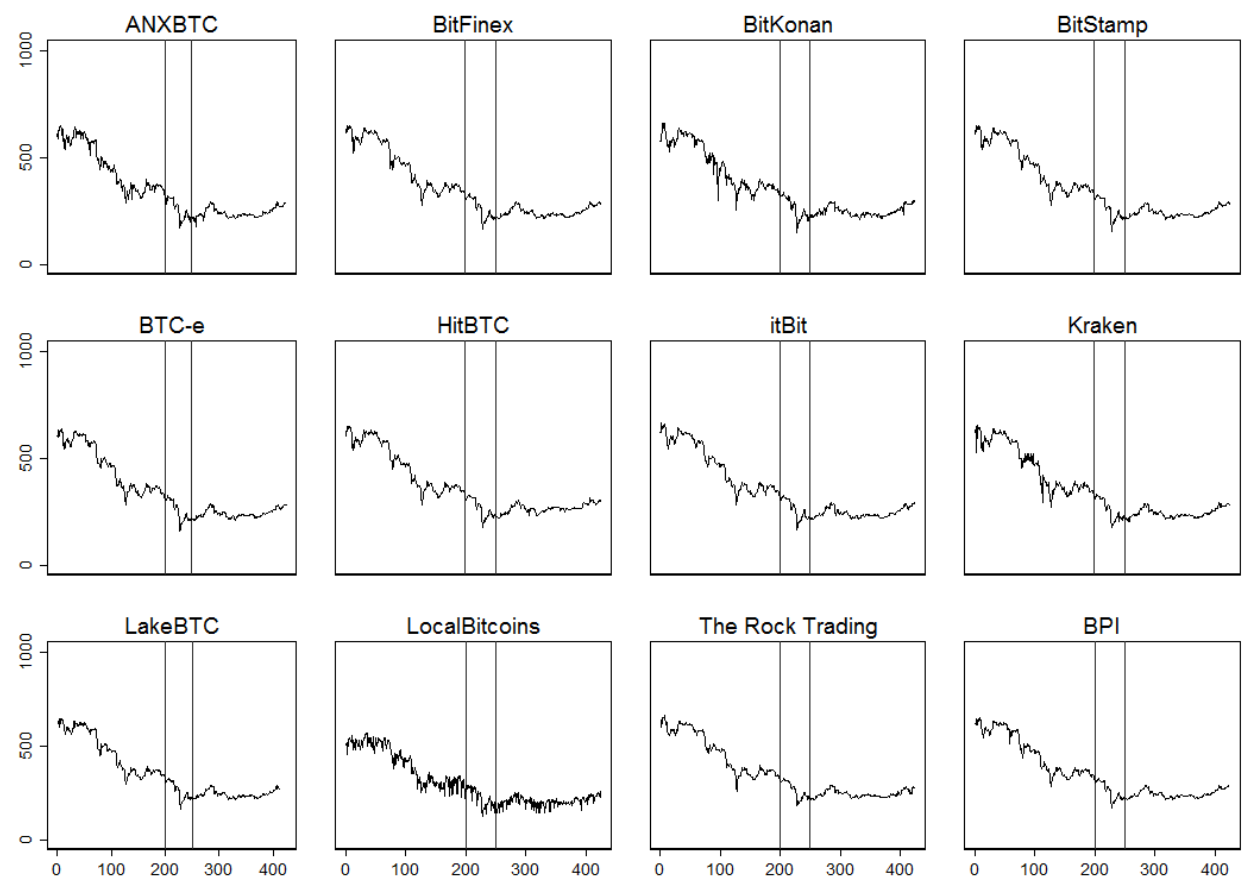

Figure 7: High Prices
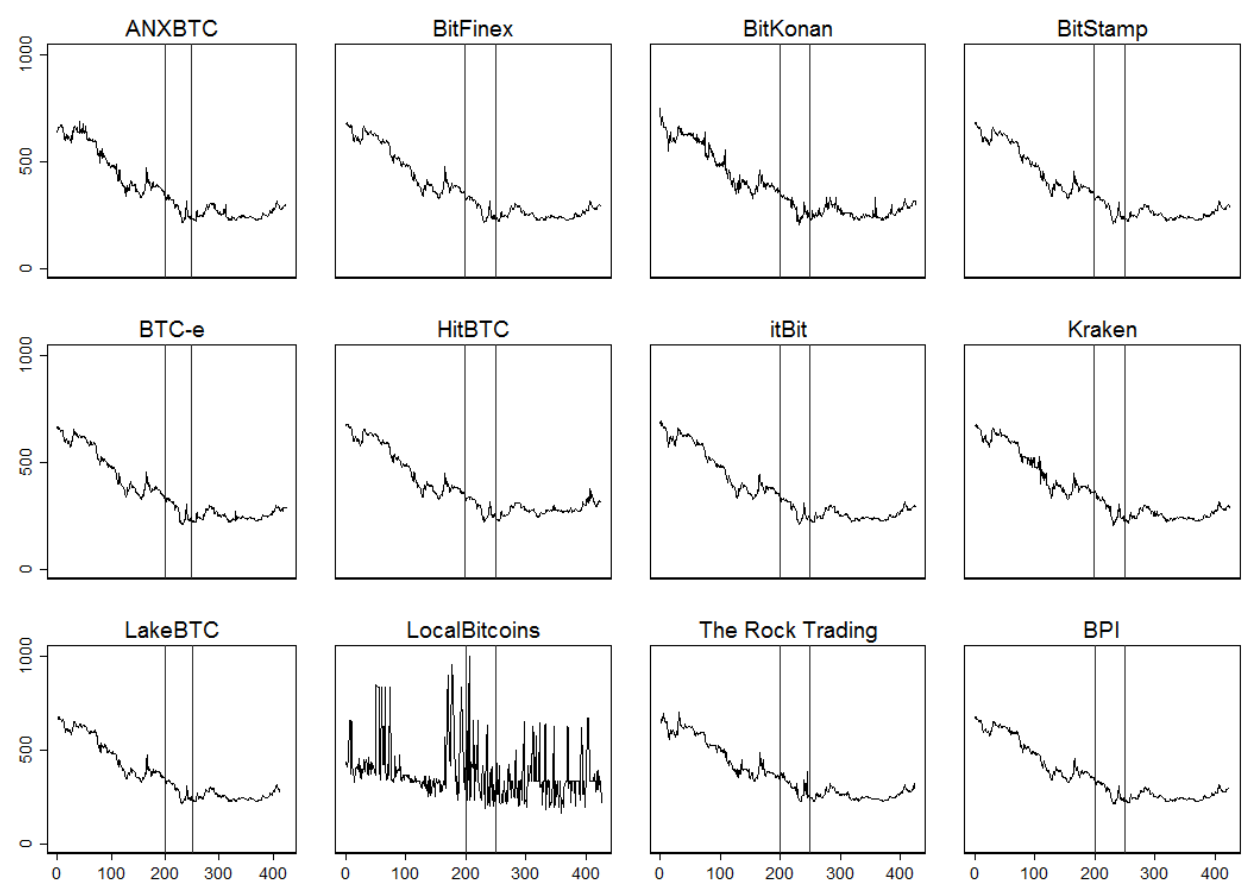


\section{B.2 Differences between exchange prices and BitFinex}

Figures (8)-(12) plot the difference between the price-series of the indicated exchange and BitFinex, $p_{t}^{i}-$

$p_{t}^{\text {BitFinex }}$. A trend line constructed with a Lowess smoother is included. The two vertical lines denote the end of the first segment and beginning of the second segment for the structural break exercise in section 4.3.2.

Figure 8: Difference in Open Prices
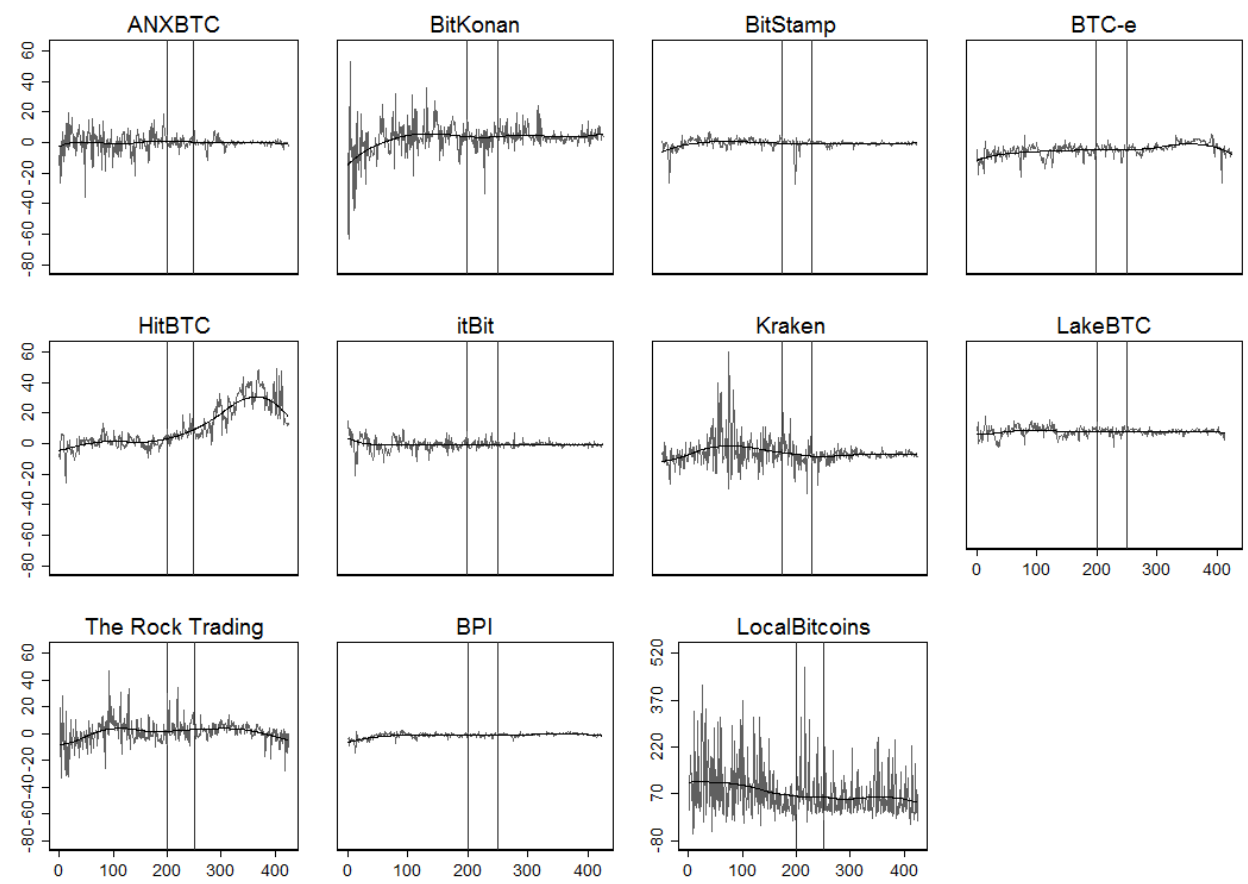
Figure 9: Difference in Close Prices
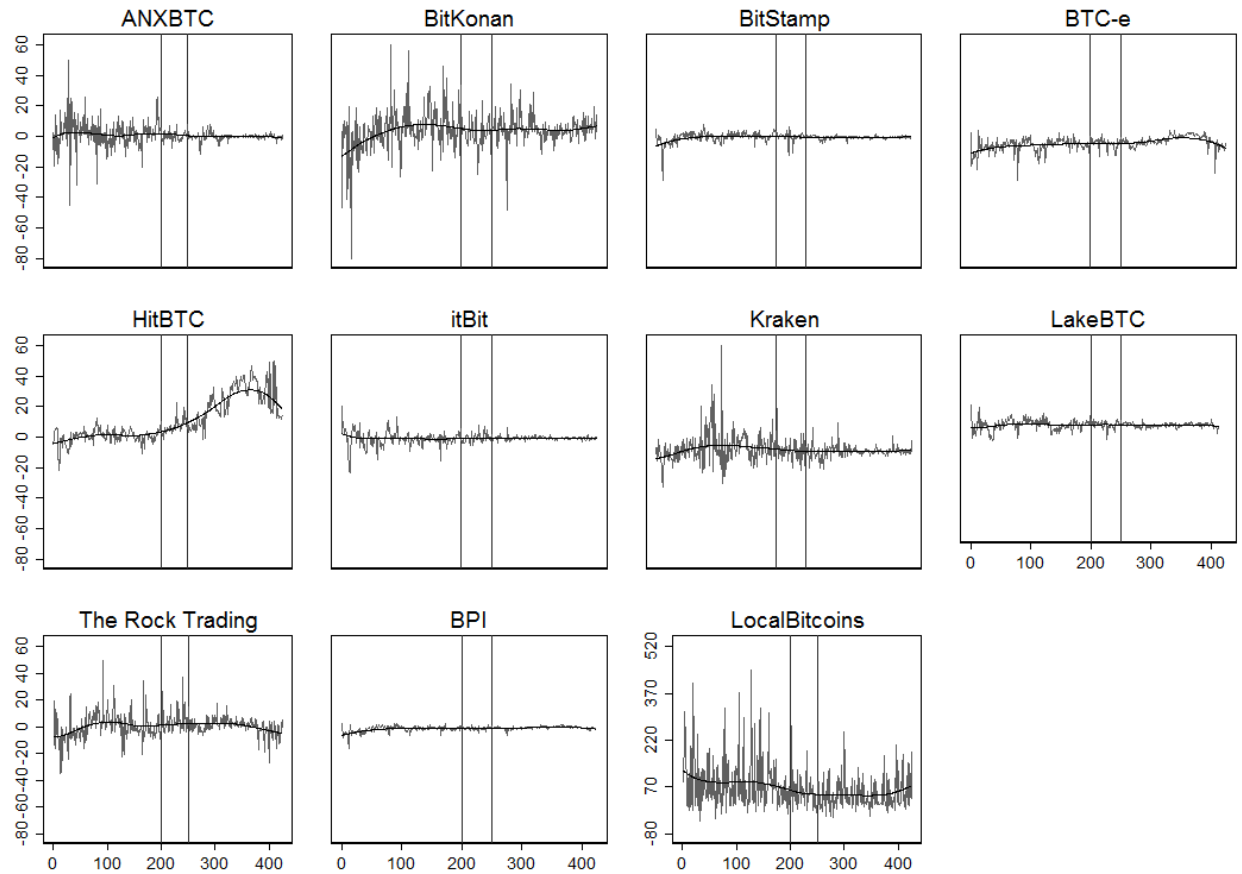

Figure 10: Difference in Weighted Prices
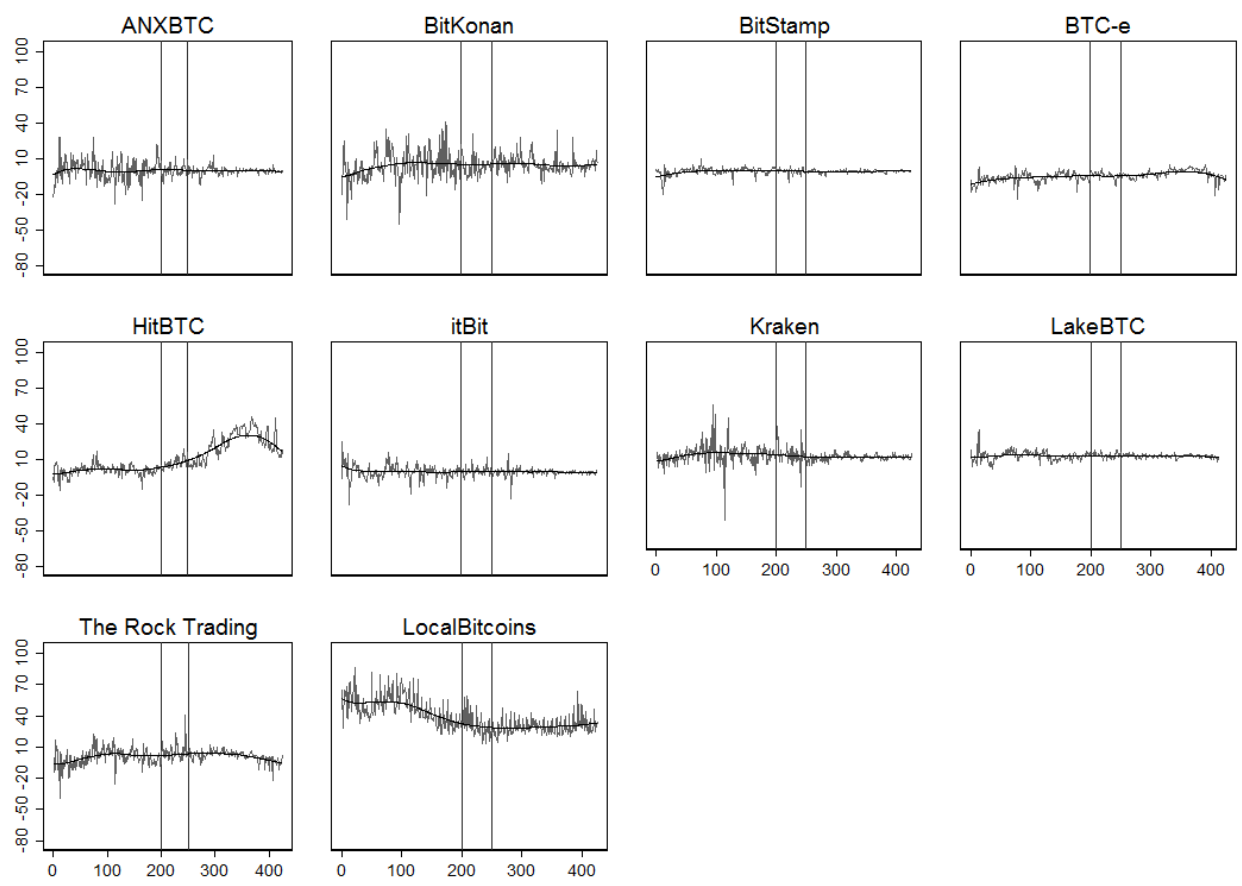
Figure 11: Difference in Low Prices
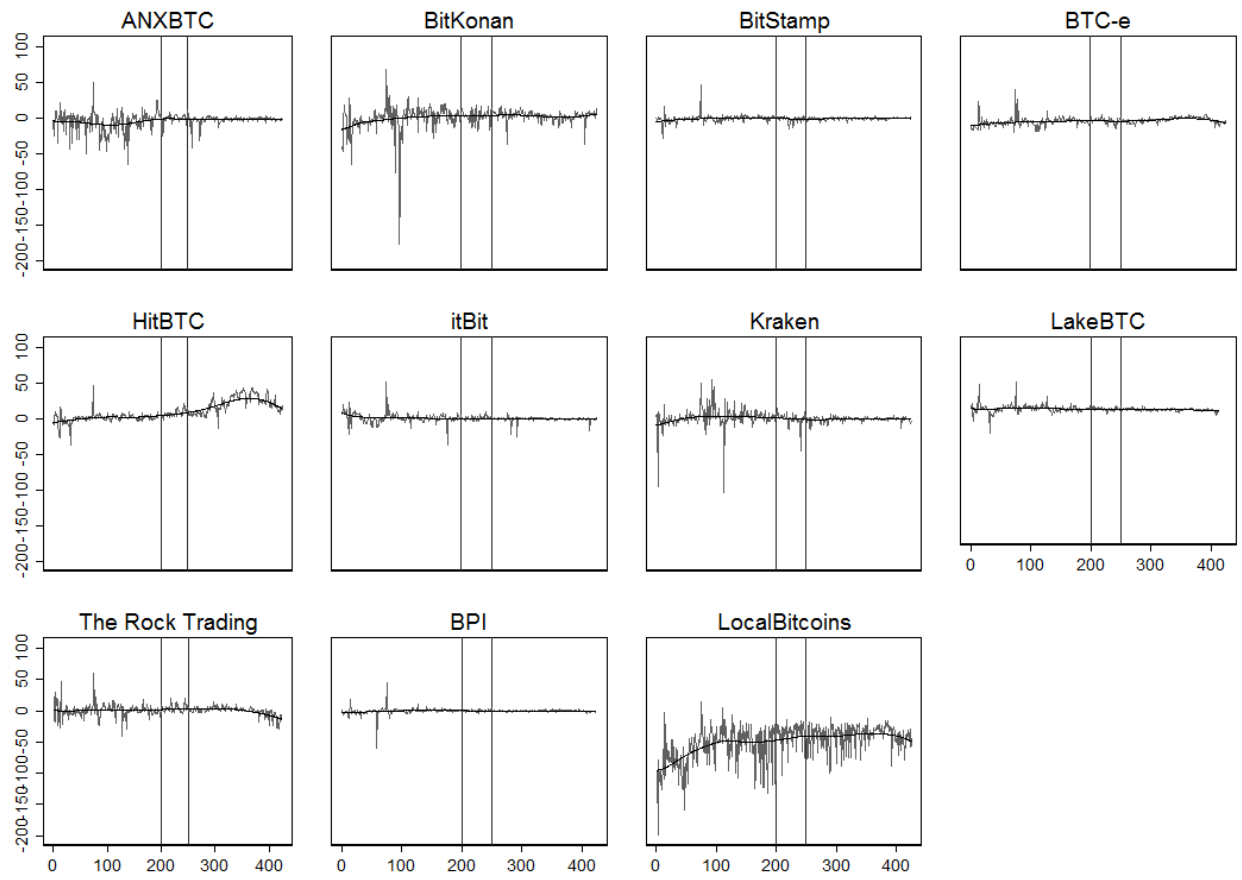

Figure 12: Difference in High Prices
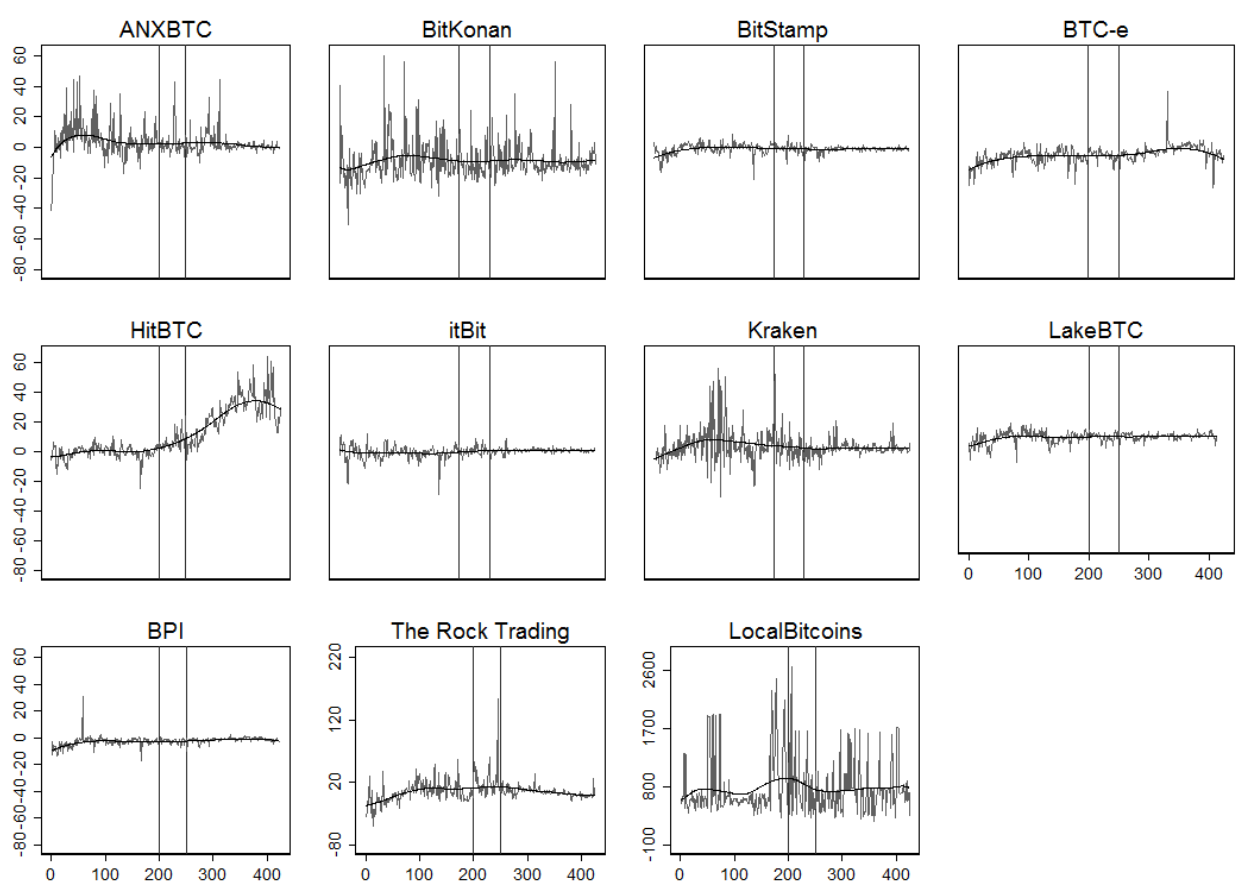


\section{B.3 Cointegration results, all series}

For completeness, tables (15) - (17) contain the results of cointegration tests for all exchanges relative to all other exchanges, using the methods of section 4.1. If a series does not affirm unit root, a result of $N G C$ indicates a single direction of granger-causality could not be established. An $N C$ indicates that cointegration was not found, while $\ell>15$ indicates that the series residual displayed auto-correlation up to lag 15 . If none of these issues were found, the cointegration parameter, $\beta$ is reported. All $\beta$ results are significant at $1 \%$. The results relative to BitFinex (the first column) are the results reported in section 4.2. LOOP status is transitive: any series that consistently achieves LOOP with BitFinex has LOOP with any other series that does the same. As documented in section 4.3.1, if a series does not achieve LOOP with BitFinex it does not achieve LOOP with any other series.

Table 15: Cointegration with All Series, Open Prices

\begin{tabular}{|l|c|ccccc|ccccc|}
\hline & BitF & ANX & BitK & BitS & BTC-e & HitBTC & itBit & Kraken & Lake & Local & Rock \\
\hline ANXBTC & 1.00 & - & - & - & - & - & - & - & - & - & - \\
BitKonan & $\ell>15$ & 0.98 & - & - & - & - & - & - & - & - & - \\
BitStamp & 1.00 & 1.00 & $\ell>15$ & - & - & - & - & - & - & - & - \\
BTC-e & 0.99 & 0.99 & $\ell>15$ & 0.99 & - & - & - & - & - & - & - \\
HitBTC & $N C$ & $N C$ & $\ell>15$ & $N C$ & $N C$ & - & - & - & - & - & - \\
itBit & 1.00 & 1.00 & $\ell>15$ & 1.00 & 1.01 & $N C$ & - & - & - & - & - \\
Kraken & 1.01 & 1.00 & 1.02 & 1.00 & 1.02 & $N C$ & 1.01 & - & - & - & - \\
Lake & 1.00 & 1.00 & $\ell>15$ & 1.00 & 1.01 & $N C$ & 1.00 & 0.99 & - & - & - \\
Local & 1.14 & 1.14 & $N G C$ & 1.14 & 1.16 & 1.21 & 1.14 & 1.13 & 1.14 & - & - \\
Rock & 0.98 & 0.98 & 1.00 & 0.98 & 0.99 & $N C$ & 0.99 & 0.98 & 0.99 & 1.15 & - \\
BPI & 1.00 & 0.99 & $\ell>15$ & 1.00 & 1.01 & $N C$ & 1.00 & 0.99 & 1.00 & 1.15 & $\ell>15$ \\
\hline
\end{tabular}

Abbreviations: $\ell>15$, Lag to avoid residual autocorrelation greater than 15 days; NC, Not Cointegrated. NGC, Could not establish single direction granger-causality.

Table 16: Cointegration with All Series, Close Prices

\begin{tabular}{|l|c|ccccc|ccccc|}
\hline & BitF & ANX & BitK & BitS & BTC-e & HitBTC & itBit & Kraken & Lake & Local & Rock \\
\hline ANXBTC & 1.01 & - & - & - & - & - & - & - & - & - & - \\
BitKonan & 0.98 & 0.98 & - & - & - & - & - & - & - & - & - \\
BitStamp & 1.00 & 0.99 & 1.01 & - & - & - & - & - & - & - & - \\
BTC-e & 0.99 & 0.98 & 1.01 & 0.99 & - & - & - & - & - & - & - \\
HitBTC & $N C$ & $N C$ & $N C$ & $N C$ & $N C$ & - & - & - & - & - & - \\
itBit & 1.00 & 0.99 & 1.01 & 1.00 & 1.01 & $N C$ & - & - & - & - & - \\
Kraken & 1.00 & 1.00 & 1.02 & 1.00 & 1.01 & $N C$ & 1.00 & - & - & - & - \\
Lake & 1.00 & 0.99 & 1.02 & 1.00 & 1.01 & $N C$ & 1.01 & 1.00 & - & - & - \\
Local & 1.13 & 1.13 & 1.13 & 1.13 & 1.14 & 1.20 & 1.13 & 1.14 & 1.13 & - & - \\
Rock & 0.99 & 0.98 & 1.00 & 0.99 & 1.00 & $N C$ & 0.99 & 0.98 & 0.99 & 1.15 & - \\
BPI & 1.00 & 0.99 & 1.01 & 1.00 & 1.01 & $N C$ & 1.00 & 0.99 & 1.00 & 1.14 & 1.00 \\
\hline
\end{tabular}

Abbreviations: NC, Not Cointegrated. 
Table 17: Cointegration with All Series, Weighted Prices

\begin{tabular}{|l|c|ccccc|cccc|}
\hline & BitF & ANX & BitK & BitS & BTC-e & HitBTC & itBit & Kraken & Lake & Local \\
\hline ANXBTC & 1.00 & - & - & - & - & - & - & - & - & - \\
BitKonan & 0.99 & 0.99 & - & - & - & - & - & - & - & - \\
BitStamp & 1.00 & 0.99 & 1.01 & - & - & - & - & - & - & - \\
BTC-e & 0.99 & 0.98 & 1.00 & 0.99 & - & - & - & - & - & - \\
HitBTC & $N C$ & $N C$ & $N C$ & $N C$ & $N C$ & - & - & - & - & - \\
itBit & 1.00 & 0.99 & 1.01 & 1.00 & 1.01 & $N C$ & - & - & - & - \\
Kraken & 1.00 & 1.00 & 1.01 & 1.01 & 1.02 & $N C$ & 1.01 & - & - & - \\
Lake & 1.00 & 0.99 & 1.01 & 1.00 & 1.01 & $N C$ & 1.00 & 1.00 & - & - \\
Local & $\ell>15$ & $\ell>15$ & 1.08 & $\ell>15$ & $\ell>15$ & $\ell>15$ & $\ell>15$ & 1.07 & $\ell>15$ & - \\
Rock & 0.98 & 0.98 & 1.00 & 0.99 & 0.99 & $N C$ & 0.98 & 0.98 & 0.98 & 0.92 \\
\hline
\end{tabular}

Abbreviations: $\ell>15$, Lag to avoid residual autocorrelation greater than 15 days; NC, Not Cointegrated.

Table 18: Cointegration with All Series, Low Prices

\begin{tabular}{|l|c|ccccc|ccccc|}
\hline & BitF & ANX & BitK & BitS & BTC-e & HitBTC & itBit & Kraken & Lake & Local & Rock \\
\hline ANXBTC & 0.98 & - & - & - & - & - & - & - & - & - & - \\
BitKonan & 0.98 & 0.99 & - & - & - & - & - & - & - & - & - \\
BitStamp & 1.00 & 1.01 & 1.02 & - & - & - & - & - & - & - & - \\
BTC-e & 0.99 & 1.00 & 1.02 & 0.99 & - & - & - & - & - & - & - \\
HitBTC & $N C$ & 0.95 & $N C$ & $N C$ & $N C$ & - & - & - & - & - & - \\
itBit & 1.00 & 1.02 & 1.03 & 1.01 & 1.01 & $N C$ & - & - & - & - & - \\
Kraken & 1.00 & 1.03 & 1.03 & 1.01 & 1.02 & 1.09 & 1.01 & - & - & - & - \\
Lake & 1.00 & 1.02 & 1.02 & 1.01 & 1.01 & $N C$ & 1.00 & 1.00 & - & - & - \\
Local & 0.89 & 0.91 & 0.91 & 0.90 & 0.91 & 0.95 & 0.90 & 0.89 & 0.89 & - & - \\
Rock & $\ell>15$ & 1.01 & 1.02 & $\ell>15$ & $\ell>15$ & $\ell>15$ & 0.99 & 0.98 & 0.99 & 0.90 & - \\
BPI & 1.00 & 1.01 & 1.02 & 1.00 & 1.01 & $N C$ & 0.99 & 0.99 & 0.99 & 0.90 & $\ell>15$ \\
\hline
\end{tabular}

Abbreviations: $\ell>15$, Lag to avoid residual autocorrelation greater than 15 days; NC, Not Cointegrated.

Table 19: Cointegration with All Series, High Prices

\begin{tabular}{|l|c|ccccc|ccccc|}
\hline & BitF & ANX & BitK & BitS & BTC-e & HitBTC & itBit & Kraken & Lake & Local & Rock \\
\hline ANXBTC & 1.02 & - & - & - & - & - & - & - & - & - & - \\
BitKonan & 0.99 & 0.98 & - & - & - & - & - & - & - & - & - \\
BitStamp & 1.00 & 0.98 & 1.01 & - & - & - & - & - & - & - & - \\
BTC-e & 0.98 & 0.97 & 0.99 & 0.99 & - & - & - & - & - & - & - \\
HitBTC & $N C$ & $N C$ & 0.95 & $N C$ & $N C$ & - & - & - & - & - & - \\
itBit & 0.99 & 0.97 & 1.01 & 1.00 & 1.01 & 1.07 & - & - & - & - & - \\
Kraken & 1.00 & 0.99 & 1.01 & 1.00 & 1.02 & $N C$ & 1.01 & - & - & - & - \\
Lake & 1.00 & 0.98 & 1.00 & 1.00 & 1.01 & $N C$ & 1.00 & 0.99 & - & - & - \\
Local & 1.06 & NGC & 1.03 & 1.07 & NGC & NGC & NGC & NGC & NGC & - & - \\
Rock & 0.97 & 0.95 & 0.98 & 0.97 & 0.98 & $N C$ & 0.97 & 0.96 & 0.97 & NGC & - \\
BPI & 0.99 & 0.98 & 1.00 & 0.99 & 1.01 & $N C$ & 1.00 & 0.99 & 1.00 & NGC & 1.03 \\
\hline
\end{tabular}

Abbreviations:NC, Not Cointegrated. NGC, Could not establish single direction granger-causality.

\section{B.4 Price Deviation Results}

Tables 20 - 37 represent variations of the data and regressions presented in section 5.3. Results show a decrease in price deviations associated with a requirement of ID for funding.

\section{B.4.1 Summary Statistics}

Table 20 is an expansion of Table 9, including the Min and Max values for each exchange. 
Table 20: Detailed Summary Statistics, Price Deviation and Trade Volume

\begin{tabular}{|c|c|c|c|c|c|c|c|}
\hline market & & Open & Close & Weighted & High & Low & TVR \\
\hline \multirow[t]{4}{*}{ ANXBTC } & Mean & -5.47 & -5.32 & -5.08 & -4.99 & -4.88 & 0.08 \\
\hline & Std. Dev & 1.38 & 1.31 & 1.22 & 1.31 & 1.44 & 0.10 \\
\hline & Min & -9.88 & -10.14 & -10.45 & -9.53 & -9.83 & 0.00 \\
\hline & Max & -2.86 & -2.47 & -2.72 & -1.65 & -1.64 & 0.80 \\
\hline \multirow[t]{4}{*}{ BitKonan } & Mean & -4.35 & -4.09 & -4.23 & -4.09 & -4.16 & 0.00 \\
\hline & Std. Dev & 1.06 & 1.11 & 1.17 & 1.31 & 1.19 & 0.00 \\
\hline & Min & -10.22 & -8.15 & -9.46 & -8.85 & -10.13 & 0.00 \\
\hline & Max & -1.92 & -1.68 & -1.94 & -1.00 & -0.99 & 0.01 \\
\hline \multirow[t]{4}{*}{ BitStamp } & Mean & -6.08 & -6.07 & -6.00 & -5.77 & -5.75 & 0.63 \\
\hline & Std. Dev & 1.26 & 1.27 & 1.20 & 1.24 & 1.27 & 0.38 \\
\hline & Min & -10.52 & -10.66 & -10.50 & -10.09 & -10.55 & 0.17 \\
\hline & Max & -2.39 & -2.84 & -3.33 & -3.11 & -2.28 & 3.31 \\
\hline \multirow[t]{4}{*}{ BTC-e } & Mean & -4.59 & -4.64 & -4.60 & -4.50 & -4.64 & 0.41 \\
\hline & Std. Dev & 0.93 & 1.00 & 0.93 & 0.87 & 1.06 & 0.24 \\
\hline & Min & -10.07 & -9.38 & -9.78 & -9.39 & -10.47 & 0.02 \\
\hline & Max & -2.46 & -2.56 & -2.65 & -1.84 & -2.42 & 2.88 \\
\hline \multirow[t]{4}{*}{ HitBTC } & Mean & -4.05 & -3.99 & -4.01 & -4.10 & -3.93 & 0.04 \\
\hline & Std. Dev & 1.64 & 1.59 & 1.59 & 1.77 & 1.52 & 0.06 \\
\hline & Min & -9.39 & -9.15 & -8.97 & -10.98 & -9.49 & 0.00 \\
\hline & Max & -1.52 & -1.56 & -1.59 & -1.36 & -1.63 & 0.44 \\
\hline \multirow[t]{4}{*}{ itBit } & Mean & -5.70 & -5.72 & $\begin{array}{c}-5.44 \\
\end{array}$ & $\begin{array}{c}-5.23 \\
\end{array}$ & -5.52 & 0.16 \\
\hline & Std. Dev. & 1.18 & 1.20 & 1.20 & 1.04 & 1.36 & 0.17 \\
\hline & Min & -11.10 & -10.95 & -10.10 & -10.98 & -10.52 & 0.00 \\
\hline & Max & -3.35 & -3.26 & -2.55 & -2.76 & -2.16 & 1.43 \\
\hline \multirow[t]{4}{*}{ Kraken } & Mean & -4.85 & -4.77 & -5.02 & -4.79 & -4.92 & 0.00 \\
\hline & Std. Dev. & 1.36 & 1.25 & 1.36 & 1.24 & 1.26 & 0.00 \\
\hline & Min & -11.05 & -10.29 & -10.39 & -9.08 & -9.03 & 0.00 \\
\hline & Max & -1.67 & -1.69 & -1.89 & -1.89 & -1.35 & 0.01 \\
\hline \multirow[t]{4}{*}{ LakeBTC } & Mean & -5.41 & -5.39 & -5.39 & -5.32 & -5.17 & 0.30 \\
\hline & Std. Dev & 1.05 & 1.00 & 1.07 & 1.08 & 1.05 & 0.27 \\
\hline & Min & -10.16 & -9.37 & -10.14 & -10.69 & -9.27 & 0.02 \\
\hline & Max & -3.08 & -3.15 & -3.07 & -3.29 & -2.31 & 2.92 \\
\hline \multirow[t]{4}{*}{ LocalBitcoins } & Mean & $\begin{array}{l}-2.02 \\
\end{array}$ & -2.09 & -2.24 & 0.78 & -2.06 & 0.10 \\
\hline & Std. Dev & 1.17 & 1.14 & 0.28 & 0.65 & 0.50 & 0.09 \\
\hline & Min & -9.66 & -6.92 & -3.14 & -0.41 & -5.27 & 0.00 \\
\hline & Max & 0.64 & 0.55 & -1.37 & 3.15 & -1.01 & 0.51 \\
\hline \multirow[t]{4}{*}{ The Rock Trading } & Mean & -4.51 & -4.61 & -4.56 & -4.14 & -4.71 & 0.00 \\
\hline & Std. Dev & 1.12 & 1.17 & 1.07 & 1.28 & 1.34 & 0.00 \\
\hline & Min & -9.57 & -10.20 & -9.93 & -9.89 & -9.15 & 0.00 \\
\hline & Max & -2.04 & -2.00 & -1.71 & -0.42 & -2.01 & 0.01 \\
\hline
\end{tabular}

\section{B.4.2 Single Exchange Characteristic}

Tables (21)-(25) report single effect results from the OLS regression on price deviation (regression (i) in Table 11). Results of statistically significant variables usually retain the same sign regardless of which price-series is used. There are only two exceptions, both of which occur for the High price: regression (viii) (Fixed Trading Fee) and regression (ix) (Indicator for Low Global Share), which increase deviations for all except 
the High price-series.

Table 21: Price Deviation and Single Exchange Characteristics, OPEN price-series

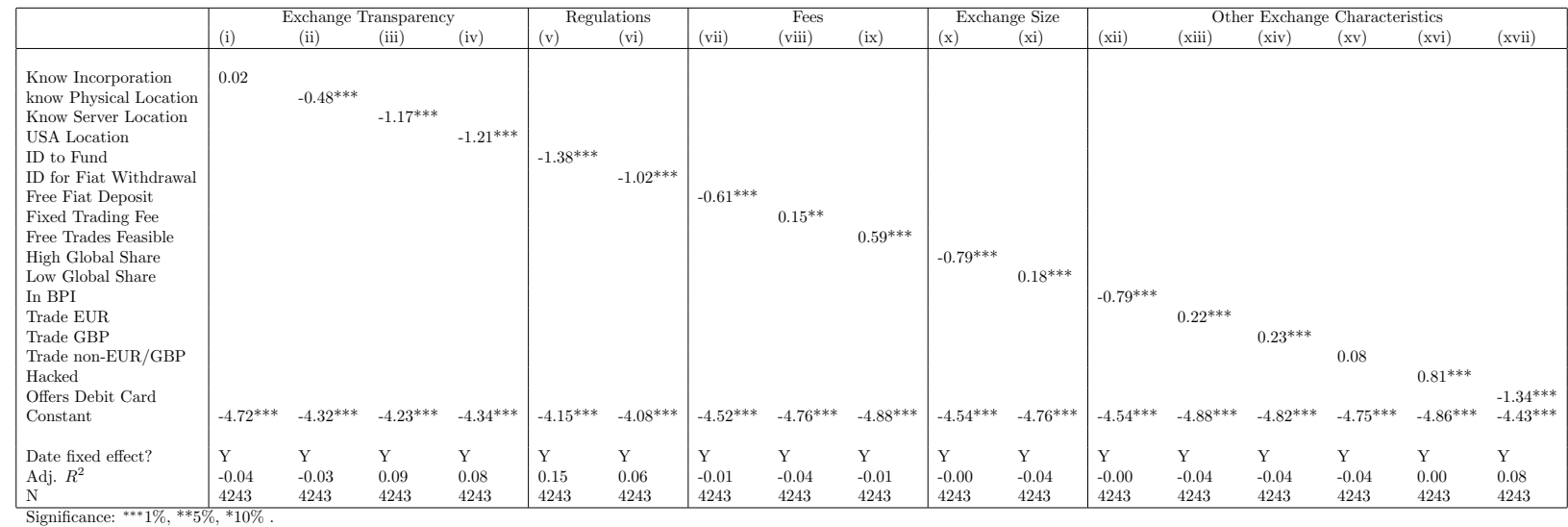

Table 22: Price Deviation and Single Exchange Characteristics, CLOSE price-series

\begin{tabular}{|c|c|c|c|c|c|c|c|c|c|c|c|c|c|c|c|c|c|}
\hline & \multirow{2}{*}{\multicolumn{4}{|c|}{$\begin{array}{l}\begin{array}{l}\text { Exchange Transparency } \\
\text { (ii) }\end{array} \\
\text { (iii) }\end{array}$}} & \multirow{2}{*}{\multicolumn{2}{|c|}{$\begin{array}{l}\text { Regulations } \\
\text { (v) }\end{array}$}} & \multicolumn{3}{|c|}{ Fees } & \multicolumn{2}{|c|}{ Exchange Size } & \multicolumn{6}{|c|}{ Other Exchange Characteristics } \\
\hline & & & & & & & (vii) & (viii) & (ix) & (x) & (xi) & (xii) & (xiii) & (xiv) & $(\mathrm{xv})$ & (xvi) & (xvii) \\
\hline $\begin{array}{l}\text { Know Incorporation } \\
\text { Know Physical Location } \\
\text { Know Server } \\
\text { USA Location } \\
\text { ID to Fund } \\
\text { ID for Fiat Withdrawal } \\
\text { Free Fiat Deposit } \\
\text { Fixed Trading Fee } \\
\text { Free Trades Feasible } \\
\text { High Global Share } \\
\text { Low Global Share } \\
\text { In BPI } \\
\text { Trade EUR } \\
\text { Trade GBP } \\
\text { Trade non-EUR/GBP } \\
\text { Hacked } \\
\text { Offers Debit Card }\end{array}$ & 0.02 & $-0.44^{* * *}$ & $-1.06^{* * *}$ & $-1.22^{* * * *}$ & $-1.34^{* * *}$ & $-1.03^{* * *}$ & $-0.62^{* * *}$ & $0.26^{* * *}$ & $0.58^{* * * *}$ & $-0.86^{* * *}$ & $0.25^{* * *}$ & $-0.86^{* * *}$ & 0.08 & $0.19^{* * *}$ & 0.04 & $0.73^{* * *}$ & $-1.28^{* * *}$ \\
\hline $\begin{array}{l}\text { Constant } \\
\text { Date fixed effect? } \\
\text { Adj. } R^{2} \\
\text { N }\end{array}$ & $\begin{array}{l}-4.68^{* * *} \\
Y \\
-0.03 \\
4243 \\
\end{array}$ & $\begin{array}{l}-4.31 * * * \\
Y \\
-0.02 \\
4243 \\
\end{array}$ & $\begin{array}{l}-4.24^{* * *} \\
Y \\
0.08 \\
4243 \\
\end{array}$ & $\begin{array}{l}-4.30^{* * *} \\
Y \\
0.10 \\
4243 \\
\end{array}$ & $\begin{array}{l}-4.13^{* * *} \\
Y \\
0.15 \\
4243 \\
\end{array}$ & $\begin{array}{l}-4.04^{* * *} \\
Y \\
0.08 \\
4243 \\
\end{array}$ & $\begin{array}{l}-4.48^{* * *} \\
Y \\
0.00 \\
4243 \\
\end{array}$ & $\begin{array}{l}-4.77^{* * *} \\
Y \\
-0.03 \\
4243 \\
\end{array}$ & \begin{tabular}{l|}
$-4.84^{* * *}$ \\
$Y$ \\
-0.00 \\
4243
\end{tabular} & $\begin{array}{l}-4.49^{* * *} \\
\mathrm{Y} \\
0.02 \\
4243 \\
\end{array}$ & $\begin{array}{l}-4.74^{* * *} \\
Y \\
-0.03 \\
4243 \\
\end{array}$ & $\begin{array}{l}-4.49^{* * *} \\
\mathrm{Y} \\
0.02 \\
4243 \\
\end{array}$ & $\begin{array}{l}-4.73^{* * *} \\
Y \\
-0.03 \\
4243 \\
\end{array}$ & $\begin{array}{l}-4.76^{* * *} \\
Y \\
-0.03 \\
4243 \\
\end{array}$ & $\begin{array}{l}-4.69^{* * *} \\
Y \\
-0.03 \\
4243 \\
\end{array}$ & $\begin{array}{l}-4.81 * * * \\
Y \\
0.00 \\
4243 \\
\end{array}$ & $\begin{array}{l}-4.41 * * * \\
Y \\
0.08 \\
4243 \\
\end{array}$ \\
\hline
\end{tabular}

Table 23: Price Deviation and Single Exchange Characteristics, WEIGHTED price-series

\begin{tabular}{|c|c|c|c|c|c|c|c|c|c|c|c|c|c|c|c|c|c|}
\hline & \multicolumn{4}{|c|}{ Exchange Transparency } & \multicolumn{2}{|c|}{ Regulations } & \multicolumn{3}{|c|}{ Fees } & \multicolumn{2}{|c|}{ Exchange Size } & \multicolumn{6}{|c|}{ Other Exchange Characteristics } \\
\hline & (i) & (ii) & (iii) & (iv) & (v) & (vi) & (vii) & (viii) & (ix) & $(\mathrm{x})$ & (xi) & (xii) & (xiii) & (xiv) & $(\mathrm{xv})$ & (xvi) & (xvii) \\
\hline Know Incorporation & 0.04 & & & & & & & & & & & & & & & & \\
\hline Know Physical Location & & $-0.43^{* * *}$ & $-0.89 * * *$ & & & & & & & & & & & & & & \\
\hline USA Location & & & & $-1.19^{* * *}$ & & & & & & & & & & & & & \\
\hline ID to Fund & & & & & $-1.22^{* * *}$ & & & & & & & & & & & & \\
\hline ID for Fiat Withdrawal & & & & & & $-0.91 * * *$ & & & & & & & & & & & \\
\hline Free Fiat Deposit & & & & & & & $-0.50^{* * * *}$ & $0.29^{* * *}$ & & & & & & & & & \\
\hline $\begin{array}{l}\text { Fixed Irading Fee } \\
\text { Free Trades Feasible }\end{array}$ & & & & & & & & & $0.61^{* * *}$ & & & & & & & & \\
\hline High Global Share & & & & & & & & & & $-0.81^{* * *}$ & & & & & & & \\
\hline $\begin{array}{l}\text { Low Global Share } \\
\text { In BPI }\end{array}$ & & & & & & & & & & & 0.07 & $-0.81 * * *$ & & & & & \\
\hline Trade EUR & & & & & & & & & & & & & $0.18^{* * *}$ & & & & \\
\hline Trade GBP & & & & & & & & & & & & & & $0.15^{* *}$ & & & \\
\hline Trade Non-EUR/GBP & & & & & & & & & & & & & & & 0.08 & & \\
\hline $\begin{array}{l}\text { Hacked } \\
\text { Offers Debit Card }\end{array}$ & & & & & & & & & & & & & & & & $0.68^{* * *}$ & $-1.10^{* * * *}$ \\
\hline Constant & $-4.69^{* * *}$ & $-4.31^{* * *}$ & $-4.30^{* * *}$ & $-4.30^{* * *}$ & $-4.17^{* * *}$ & $-4.11^{* * *}$ & $-4.50^{* * *}$ & $-4.77^{* * *}$ & $-4.84^{* * *}$ & $-4.49^{* * *}$ & $-4.67^{* * *}$ & $-4.49^{* * *}$ & $-4.80^{* * *}$ & $-4.73^{* * *}$ & $-4.70^{* * *}$ & $-4.79^{* * *}$ & $-4.43^{* * *}$ \\
\hline Date fixed effect? & $\mathrm{Y}$ & Y & $\mathrm{Y}$ & $\mathrm{Y}$ & Y & $\mathrm{Y}$ & $\mathrm{Y}$ & $\mathrm{Y}$ & $\mathrm{Y}$ & $\mathrm{Y}$ & $\mathrm{Y}$ & Y & $\mathrm{Y}$ & Y & $\mathrm{Y}$ & Y & $\mathrm{Y}$ \\
\hline Adj. $R^{2}$ & -0.02 & -0.01 & 0.07 & 0.12 & 0.15 & 0.07 & 0.00 & -0.01 & 0.01 & 0.03 & -0.02 & 0.03 & -0.02 & -0.02 & -0.02 & 0.01 & 0.07 \\
\hline $\mathrm{N}$ & 4238 & 4238 & 4238 & 4238 & 4238 & 4238 & 4238 & 4238 & 4238 & 4238 & 4238 & 4238 & 4238 & 4238 & 4238 & 4238 & 4238 \\
\hline
\end{tabular}


Table 24: Price Deviation and Single Exchange Characteristics, HIGH price-series

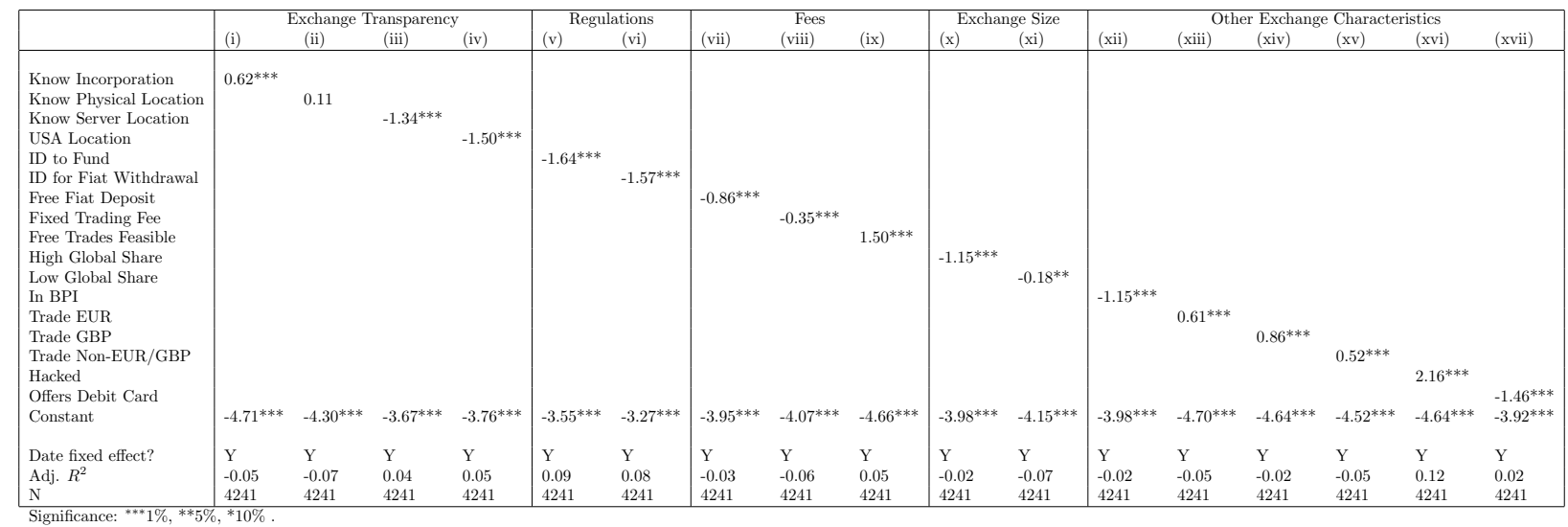

Table 25: Price Deviation and Single Exchange Characteristics, LOW price-series

\begin{tabular}{|c|c|c|c|c|c|c|c|c|c|c|c|c|c|c|c|c|c|}
\hline & & Exchange 1 & ransparenc & & Regul: & ations & & Fees & & Exchan & gige Size & & Othe & r Exchange & Character & istics & \\
\hline $\begin{array}{l}\text { Know Incorpation } \\
\text { Know Physical Location } \\
\text { Know Server Location } \\
\text { USA Location } \\
\text { ID to Fund } \\
\text { ID for Fiat Withdrawal } \\
\text { Free Fiat Deposit } \\
\text { Fixed Trading Fee } \\
\text { Free Trading Fee } \\
\text { High Global Share } \\
\text { Low Global Share } \\
\text { In BPI } \\
\text { EUR Trade } \\
\text { GBP Trader } \\
\text { Trade Non-EUR/GBP } \\
\text { Hacked } \\
\text { Offers Debit Card } \\
\text { Constant }\end{array}$ & -0.03 & $-0.35^{* * *}$ & $-0.84^{* * *}$ & $-1.18^{* * *}$ & $-1.16^{* * *}$ & $-0.95^{* * *}$ & $\mid-0.49^{* * *}$ & 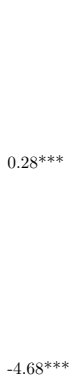 & 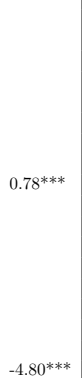 & $-0.78^{* * *}$ & -0.04 & $-0.78^{* * * *}$ & $0.11^{*}$ & $0.22^{* * *}$ & $0.11^{*}$ & $\begin{array}{l}0.85^{* * *} \\
-4.74^{* * *}\end{array}$ & $\begin{array}{l}-0.93^{* * *} \\
-4.38^{* * *}\end{array}$ \\
\hline $\begin{array}{l}\text { Date fixed effect? } \\
\text { Adj. } R^{2} \\
\mathrm{~N}\end{array}$ & \begin{tabular}{|l|}
$Y$ \\
-0.01 \\
4233 \\
\end{tabular} & $\begin{array}{l}\mathrm{Y} \\
-0.00 \\
4233 \\
\end{array}$ & $\begin{array}{l}\mathrm{Y} \\
0.06 \\
4233 \\
\end{array}$ & $\begin{array}{l}\mathrm{Y} \\
0.12 \\
4233 \\
\end{array}$ & $\begin{array}{l}\mathrm{Y} \\
0.13 \\
4233 \\
\end{array}$ & $\begin{array}{l}\mathrm{Y} \\
0.08 \\
4233 \\
\end{array}$ & \begin{tabular}{|l|}
$\mathrm{Y}$ \\
0.01 \\
4233 \\
\end{tabular} & $\begin{array}{l}\mathrm{Y} \\
-0.01 \\
4233 \\
\end{array}$ & $\begin{array}{l}\mathrm{Y} \\
0.04 \\
4233 \\
\end{array}$ & \begin{tabular}{|l|l}
$\mathrm{Y}$ \\
0.03 \\
4233 \\
\end{tabular} & $\begin{array}{l}Y \\
-0.01 \\
4233 \\
\end{array}$ & \begin{tabular}{|l|l}
$\mathrm{Y}$ \\
0.03 \\
4233 \\
\end{tabular} & $\begin{array}{l}\mathrm{Y} \\
-0.01 \\
4233 \\
\end{array}$ & $\begin{array}{l}\mathrm{Y} \\
-0.01 \\
4233 \\
\end{array}$ & $\begin{array}{l}Y \\
-0.01 \\
4233 \\
\end{array}$ & $\begin{array}{l}\mathrm{Y} \\
0.04 \\
4233 \\
\end{array}$ & $\begin{array}{l}\mathrm{Y} \\
0.05 \\
4233 \\
\end{array}$ \\
\hline
\end{tabular}

\section{B.4.3 Combined Exchange Characteristics}

Tables (26)-(30) examines grouped regressions of exchange characteristics for groupings that do not result in multicollinearity. The interaction of Fixed Cost to Trade and Free Trades Feasible is a fixed effect for ANXBTC, and is not used. Increases in transparency (Known Server Location) decrease deviations, as does requiring an ID to Fund or having a larger exchange. Fees increase deviations. Accepting trades in multiple foreign currencies has a mixed effect, though overall an exchange that allows for trade in Euros, GBP, and at least one other currency has larger deviations than an exchange that does not. 
Table 26: Price Deviation and Grouped Exchange Characteristics, OPEN price-series

\begin{tabular}{|c|c|c|c|c|c|c|c|c|}
\hline & Trans! & arency & Regulations & Fees & Exch & nge Size & & \\
\hline & (i) & (ii) & (iii) & (iv) & (v) & (vi) & (vii) & (viii) \\
\hline Know Server Location & $-0.88^{* * *}$ & $-0.80^{* * *}$ & & & & & & \\
\hline USA Location & $-0.87^{* * *}$ & $-0.75^{* * *}$ & & & & & & \\
\hline Server x USA & & $-0.23^{*}$ & & & & & & \\
\hline ID to Fund & & & $-1.38^{* * *}$ & & & & & \\
\hline Fixed Trade Cost & & & & $0.19^{* * *}$ & & & & \\
\hline Free Trade Feasible & & & & $0.60^{* * *}$ & & & & \\
\hline Low Global Share & & & & & $-0.21 * * *$ & -0.08 & & \\
\hline Trade Volume & & & & & $-1.62^{* * *}$ & $-1.64^{* * *}$ & & \\
\hline Low x Volume & & & & & & $-186.64^{* * *}$ & & \\
\hline EUR Trade & & & & & & & 0.09 & \\
\hline GBP Trade & & & & & & & $0.19^{* *}$ & $-1.10^{* * *}$ \\
\hline Non EUR/GBP Trade & & & & & & & 0.07 & $\begin{array}{l}-1.03^{* * *} \\
2.22^{* * *}\end{array}$ \\
\hline GBPxNon EUR/GBP & & & & & & & & $2.22^{* * *}$ \\
\hline Constant & $-4.09^{* * *}$ & $-4.11^{* * *}$ & $-4.15^{* * *}$ & $-4.96^{* * *}$ & $-4.36^{* * *}$ & $-4.35^{* * *}$ & $-4.91^{* * *}$ & $-4.20^{* * *}$ \\
\hline Date fixed effect? & & & & & & & & $\mathrm{Y}$ \\
\hline Adj. $R^{2}$ & 0.15 & 0.15 & 0.15 & -0.01 & 0.01 & 0.02 & -0.04 & 0.08 \\
\hline $\mathrm{N}$ & 4243 & 4243 & 4243 & 4243 & 4243 & 4243 & 4243 & 4243 \\
\hline
\end{tabular}

Table 27: Price Deviation and Grouped Exchange Characteristics, CLOSE price-series

\begin{tabular}{|c|c|c|c|c|c|c|c|c|}
\hline & Transp & arency & Regulations & Fees & Exch & age Size & & \\
\hline & (i) & (ii) & (iii) & (iv) & (v) & (vi) & (vii) & (viii) \\
\hline Know Server Location & $-0.74^{* * *}$ & $-0.56^{* * *}$ & & & & & & \\
\hline USA Location & $-0.94^{* * *}$ & $-0.63^{* * *}$ & & & & & & \\
\hline Server $\mathrm{x}$ USA & & $-0.56^{* * *}$ & & & & & & \\
\hline ID to Fund & & & $-1.34^{* * *}$ & & & & & \\
\hline Fixed Trade Cost & & & & $0.31^{* * *}$ & & & & \\
\hline Free Trades Feasible & & & & $0.61^{* * *}$ & & & & \\
\hline Low Global Share & & & & & $-0.15^{* *}$ & 0.05 & & \\
\hline Trade Volume & & & & & $-1.66^{* * *}$ & $-1.70^{* * *}$ & & \\
\hline Low Share x Volume & & & & & & $-284.83^{* * *}$ & & \\
\hline Trade EUR & & & & & & & -0.06 & \\
\hline Trade GBP & & & & & & & $0.21^{* * *}$ & $-1.30^{* * *}$ \\
\hline Trade Non-EUR/GBP & & & & & & & 0.04 & $-1.21^{* * *}$ \\
\hline GBP $x$ Non-EUR/GBP & & & & & & & & $2.49^{* * *}$ \\
\hline Constant & $-4.09^{* * *}$ & $-4.14^{* * *}$ & $-4.13^{* * *}$ & $-4.97 * * *$ & $-4.33^{* * *}$ & $-4.32^{* * *}$ & $-4.75^{* * *}$ & $-4.04^{* * *}$ \\
\hline Date fixed effect? & & & & & & Y & & Y \\
\hline Adj. $R^{2}$ & 0.15 & 0.15 & 0.15 & 0.01 & 0.03 & 0.04 & -0.03 & 0.13 \\
\hline $\mathrm{N}$ & 4243 & 4243 & 4243 & 4243 & 4243 & 4243 & 4243 & 4243 \\
\hline
\end{tabular}


Table 28: Price Deviation and Grouped Exchange Characteristics, WEIGHTED price-series

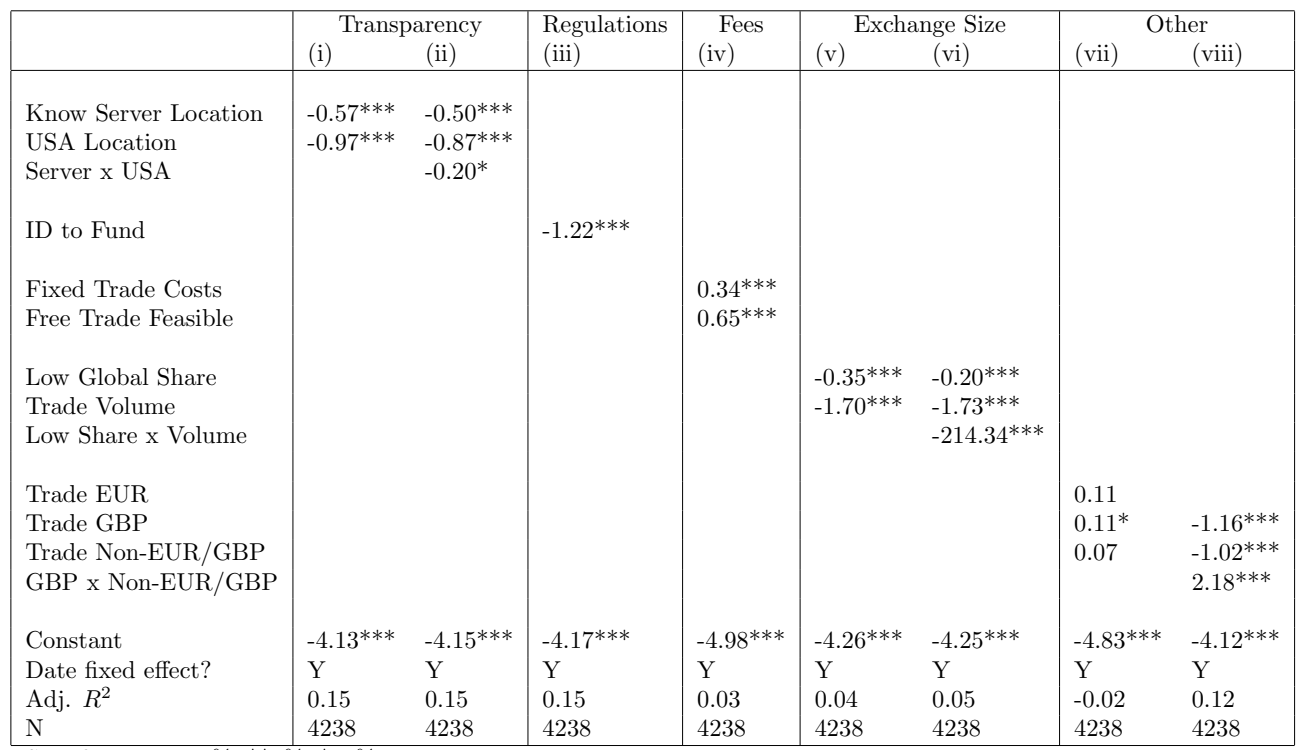

Table 29: Price Deviation and Grouped Exchange Characteristics, HIGH price-series

\begin{tabular}{|c|c|c|c|c|c|c|c|c|}
\hline & \multicolumn{2}{|c|}{ Transparency } & \multirow{2}{*}{$\begin{array}{l}\text { Regulations } \\
\text { (iii) }\end{array}$} & \multirow{2}{*}{$\begin{array}{l}\text { Fees } \\
\text { (iv) }\end{array}$} & \multicolumn{2}{|c|}{ Exchange Size } & \multicolumn{2}{|c|}{ Other } \\
\hline & (i) & (ii) & & & $(\mathrm{v})$ & (vi) & (vii) & (viii) \\
\hline Know Server Location & $-0.97^{* * *}$ & $-1.09^{* * *}$ & & & & & & \\
\hline USA Location & $-1.13^{* * *}$ & $-1.34^{* * *}$ & & & & & & \\
\hline Server x USA & & $0.39^{* * *}$ & & & & & & \\
\hline ID to Fund & & & $-1.64^{* * *}$ & & & & & \\
\hline Fixed Trade Costs & & & & $-0.23^{* * *}$ & & & & \\
\hline Free Trade Feasible & & & & $1.47^{* * *}$ & & & & \\
\hline Low Global Share & & & & & $-0.79^{* * *}$ & $-0.70^{* * *}$ & & \\
\hline Trade Volume & & & & & $-2.47^{* * *}$ & $-2.49^{* * *}$ & & \\
\hline Low Share x Volume & & & & & & $-130.52^{* *}$ & & \\
\hline Trade EUR & & & & & & & 0.00 & \\
\hline GBP Trade & & & & & & & $0.86^{* * *}$ & $-0.86^{* * *}$ \\
\hline Trade Non-EUR/GBP & & & & & & & $0.52^{* * *}$ & $-0.92^{* * *}$ \\
\hline GBP x Non-EUR/GBP & & & & & & & & $2.87^{* * *}$ \\
\hline Constant & $-3.48^{* * *}$ & $-3.45^{* * *}$ & $-3.55^{* * *}$ & $-4.56^{* * *}$ & $-3.55^{* * *}$ & $-3.54^{* * *}$ & $-4.95^{* * *}$ & $-4.09^{* * *}$ \\
\hline Date fixed effect? & $\mathrm{Y}$ & $\mathrm{Y}$ & $\mathrm{Y}$ & $\mathrm{Y}$ & $\mathrm{Y}$ & $\mathrm{Y}$ & $\mathrm{Y}$ & $\mathrm{Y}$ \\
\hline Adj. $R^{2}$ & 0.10 & 0.10 & 0.09 & 0.05 & 0.01 & 0.01 & -0.01 & 0.11 \\
\hline $\mathrm{N}$ & 4241 & 4241 & 4241 & 4241 & 4241 & 4241 & 4241 & 4241 \\
\hline
\end{tabular}




\section{B.4.4 Grouped Exchange Characteristics}

Tables (31)-(35) moves iteratively from regression (i) to regression (ii) in Table 11. The result that ID to Fund decreases deviations never changes, though the magnitude may vary. 
Table 30: Price Deviation and Grouped Exchange Characteristics, LOW price-series

\begin{tabular}{|c|c|c|c|c|c|c|c|c|}
\hline & \multicolumn{2}{|c|}{ Transparency } & \multirow{2}{*}{$\begin{array}{l}\text { Regulations } \\
\text { (iii) }\end{array}$} & \multirow{2}{*}{$\begin{array}{l}\text { Fees } \\
\text { (iv) }\end{array}$} & \multicolumn{2}{|c|}{ Exchange Size } & \multicolumn{2}{|c|}{ Other } \\
\hline & (i) & (ii) & & & $(\mathrm{v})$ & (vi) & (vii) & (viii) \\
\hline Know Server Location & $-0.52^{* * *}$ & $-0.42^{* * *}$ & & & & & & \\
\hline USA Location & $-0.98^{* * *}$ & $-0.83^{* * *}$ & & & & & & \\
\hline Know Server x USA & & $-0.29^{* *}$ & & & & & & \\
\hline ID to Fund & & & $-1.16^{* * *}$ & & & & & \\
\hline Fixed Trade Cost & & & & $0.35^{* * *}$ & & & & \\
\hline Free Trade Feasible & & & & $0.81^{* * *}$ & & & & \\
\hline Low Global Share & & & & & $-0.44^{* * *}$ & $-0.25 * * *$ & & \\
\hline Trade Volume & & & & & $-1.65^{* * *}$ & $-1.69 * * *$ & & \\
\hline Low Share x Volume & & & & & & $-274.65^{* * *}$ & & \\
\hline Trade EUR & & & & & & & -0.06 & \\
\hline Trade GBP & & & & & & & $0.25^{* * *}$ & $-1.18^{* * *}$ \\
\hline Trade Non-EUR/GBP & & & & & & & $0.11^{*}$ & $-1.06 * * *$ \\
\hline GBP x Non-EUR/GBP & & & & & & & & $2.34^{* * *}$ \\
\hline Constant & $-4.07 * * *$ & $-4.09 * * *$ & $-4.10^{* * *}$ & $-4.95 * * *$ & $-4.15^{* * *}$ & $-4.14^{* * *}$ & $-4.71 * * *$ & $-4.05^{* * *}$ \\
\hline Date fixed effect? & $\mathrm{Y}$ & $\mathrm{Y}$ & $\mathrm{Y}$ & $\mathrm{Y}$ & $\mathrm{Y}$ & $\mathrm{Y}$ & $\mathrm{Y}$ & $\mathrm{Y}$ \\
\hline Adj. $R^{2}$ & 0.14 & 0.14 & 0.13 & 0.06 & 0.04 & 0.05 & -0.01 & 0.14 \\
\hline $\mathrm{N}$ & 4233 & 4233 & 4233 & 4233 & 4233 & 4233 & 4233 & 4233 \\
\hline
\end{tabular}

Table 31: Price Deviation and Exchange Characteristics, OPEN price-series

\begin{tabular}{|c|c|c|c|c|c|c|}
\hline & (i) & (ii) & (iii) & (iv) & (v) & (vi) \\
\hline $\begin{array}{l}\text { ID to Fund } \\
\text { ID to Fund } x \text { Low Share }\end{array}$ & $-1.38^{* * *}$ & $-1.34^{* * *}$ & $\begin{array}{l}-1.66^{* * *} \\
1.22^{* * *}\end{array}$ & $-1.33^{* * *}$ & $-1.44^{* * *}$ & $\begin{array}{l}-1.92^{* * *} \\
1.50^{* * *}\end{array}$ \\
\hline Fixed Cost to Trade & & $-0.12^{*}$ & -0.04 & $-0.24^{* * *}$ & $-0.32 * * *$ & $-0.12^{*}$ \\
\hline Free Trade Feasible & & $0.58^{* * *}$ & $0.54^{* * *}$ & $0.38^{* * *}$ & $0.78^{* * *}$ & $0.83^{* * *}$ \\
\hline Low Global Share & & $0.29^{* * *}$ & $-0.16^{* *}$ & -0.09 & 0.06 & $-0.40^{* * *}$ \\
\hline Trade Volume & & & & $-1.16^{* * *}$ & $-0.77^{* * *}$ & $-0.33^{* * *}$ \\
\hline Volume $\mathrm{x}$ Fixed Cost & & & & & -0.08 & $-1.02^{* * *}$ \\
\hline Volume x Free Trade & & & & & $-2.42 * * *$ & $-3.06^{* * *}$ \\
\hline Volume x Low Share & & & & & $-94.95^{* *}$ & $-167.55^{* * *}$ \\
\hline Constant & $-4.15^{* * *}$ & $-4.38^{* * *}$ & $-4.25 * * *$ & $-3.96^{* * *}$ & $-3.97^{* * *}$ & $-3.87^{* * *}$ \\
\hline Date fixed effect? & & & & & Y & Y \\
\hline Adj. $R^{2}$ & 0.15 & 0.17 & 0.20 & 0.19 & 0.21 & 0.25 \\
\hline $\mathrm{N}$ & 4243 & 4243 & 4243 & 4243 & 4243 & 4243 \\
\hline
\end{tabular}

Significance: ${ }^{* * *} 1 \%,{ }^{* *} 5 \%,{ }^{*} 10 \%$. 
Table 32: Price Deviation and Exchange Characteristics, CLOSE price-series

\begin{tabular}{|c|c|c|c|c|c|c|}
\hline & (i) & (ii) & (iii) & (iv) & (v) & (vi) \\
\hline $\begin{array}{l}\text { ID to Fund } \\
\text { ID to Fund } x \text { Low Share }\end{array}$ & $-1.34^{* * *}$ & $-1.24^{* * *}$ & $\begin{array}{l}-1.56^{* * *} \\
1.20^{* * *}\end{array}$ & $-1.23^{* * *}$ & $-1.32^{* * *}$ & $\begin{array}{l}-1.79^{* * *} \\
1.50^{* * *}\end{array}$ \\
\hline Fixed Cost to Trade & & 0.04 & $0.12^{*}$ & -0.08 & $-0.15^{* *}$ & 0.05 \\
\hline Free Trade Feasible & & $0.65^{* * *}$ & $0.61^{* * *}$ & $0.46^{* * *}$ & $0.78^{* * *}$ & $0.82^{* * *}$ \\
\hline Low Global Share & & $0.41^{* * *}$ & -0.03 & 0.05 & $0.23^{* * *}$ & $-0.23^{* *}$ \\
\hline Trade Volume & & & & $-1.11^{* * *}$ & $-0.82^{* * *}$ & $-0.39 * * *$ \\
\hline Volume $\mathrm{x}$ Fixed Cost & & & & & -0.13 & $-1.07 * * *$ \\
\hline Volume x Free Trade & & & & & $-1.92^{* * *}$ & $-2.56^{* * *}$ \\
\hline Volume x Low Share & & & & & $-175.80^{* * *}$ & $-248.08^{* * *}$ \\
\hline Constant & $-4.13^{* * *}$ & $-4.50^{* * *}$ & $-4.38 * * *$ & $-4.10^{* * *}$ & $-4.10^{* * *}$ & $-3.99 * * *$ \\
\hline Date fixed effect? & $\mathrm{Y}$ & $\mathrm{Y}$ & $\mathrm{Y}$ & $\mathrm{Y}$ & $\mathrm{Y}$ & $\mathrm{Y}$ \\
\hline Adj. $R^{2}$ & 0.15 & 0.18 & 0.21 & 0.20 & 0.22 & 0.25 \\
\hline $\mathrm{N}$ & 4243 & 4243 & 4243 & 4243 & 4243 & 4243 \\
\hline
\end{tabular}

Significance: ${ }^{* *} 1 \%,{ }^{* *} 5 \%,{ }^{*} 10 \%$.

Table 33: Price Deviation and Exchange Characteristics, WEIGHTED price-series

\begin{tabular}{|c|c|c|c|c|c|c|}
\hline & (i) & (ii) & (iii) & (iv) & $(\mathrm{v})$ & (vi) \\
\hline $\begin{array}{l}\text { ID to Fund } \\
\text { ID to Fund } x \text { Low Share }\end{array}$ & $-1.22^{* * *}$ & $-1.13^{* * *}$ & $\begin{array}{l}-1.34^{* * *} \\
0.78^{* * *}\end{array}$ & $-1.12^{* * *}$ & $-1.22^{* * *}$ & $\begin{array}{l}-1.53^{* * *} \\
0.98^{* * *}\end{array}$ \\
\hline Fixed Cost to Trade & & 0.07 & $0.13^{* *}$ & -0.05 & $-0.12^{*}$ & 0.01 \\
\hline Free Trade Feasible & & $0.62^{* * *}$ & $0.59^{* * *}$ & $0.42^{* * *}$ & $0.75^{* * *}$ & $0.78^{* * *}$ \\
\hline Low Global Share & & $0.23^{* * *}$ & -0.06 & $-0.16^{* *}$ & -0.02 & $-0.32^{* * *}$ \\
\hline Trade Volume & & & & $-1.20^{* * *}$ & $-0.87^{* * *}$ & $-0.58^{* * *}$ \\
\hline Volume x Fixed Cost & & & & & -0.12 & $-0.73^{* * *}$ \\
\hline Volume x Free Trade & & & & & $-2.05^{* * *}$ & $-2.47 * * *$ \\
\hline Volume x Low Share & & & & & $-112.55^{* *}$ & $-159.61^{* * *}$ \\
\hline Constant & $-4.17^{* * *}$ & $-4.48^{* * *}$ & $-4.41^{* * *}$ & $-4.05^{* * *}$ & $-4.06^{* * *}$ & $-3.99^{* * *}$ \\
\hline Date fixed effect? & $\mathrm{Y}$ & $\mathrm{Y}$ & $\mathrm{Y}$ & $\mathrm{Y}$ & $\mathrm{Y}$ & $\mathrm{Y}$ \\
\hline Adj. $R^{2}$ & 0.15 & 0.18 & 0.19 & 0.21 & 0.22 & 0.24 \\
\hline $\mathrm{N}$ & 4238 & 4238 & 4238 & 4238 & 4238 & 4238 \\
\hline
\end{tabular}


Table 34: Price Deviation and Exchange Characteristics, HIGH price-series

\begin{tabular}{|c|c|c|c|c|c|c|}
\hline & (i) & (ii) & (iii) & (iv) & $(\mathrm{v})$ & (vi) \\
\hline $\begin{array}{l}\text { ID to Fund } \\
\text { ID to Fund } x \text { Low Share }\end{array}$ & $-1.64^{* * *}$ & $-1.68^{* * *}$ & $\begin{array}{l}-1.94^{* * *} \\
0.97^{* * *}\end{array}$ & $-1.67^{* * *}$ & $-1.88^{* * *}$ & $\begin{array}{l}-2.27^{* * *} \\
1.25^{* * *}\end{array}$ \\
\hline Fixed Cost to Trade & & $-0.65^{* * *}$ & $-0.58^{* * *}$ & $-0.84^{* * *}$ & $-1.00^{* * *}$ & $-0.83^{* * *}$ \\
\hline Free Trade Feasible & & $1.36^{* * *}$ & $1.33^{* * *}$ & $1.05^{* * *}$ & $1.82^{* * *}$ & $1.86^{* * *}$ \\
\hline Low Global Share & & $0.17^{* * *}$ & $-0.18^{* *}$ & $-0.42^{* * *}$ & $-0.19^{*}$ & $-0.57 * * *$ \\
\hline Trade Volume & & & & $-1.82^{* * *}$ & $-1.11^{* * *}$ & $-0.74^{* * *}$ \\
\hline Volume x Fixed Cost & & & & & 0.05 & $-0.74^{* * *}$ \\
\hline Volume x Free Trade & & & & & $-4.53^{* * *}$ & $-5.07 * * *$ \\
\hline Volume x Low Share & & & & & $-99.56^{*}$ & $-160.24^{* * *}$ \\
\hline Constant & $-3.55^{* * *}$ & $-3.73^{* * *}$ & $-3.64^{* * *}$ & $-3.08^{* * *}$ & $-3.12^{* * *}$ & $-3.03^{* * *}$ \\
\hline Date fixed effect? & $\mathrm{Y}$ & $\mathrm{Y}$ & $\mathrm{Y}$ & $\mathrm{Y}$ & $\mathrm{Y}$ & $\mathrm{Y}$ \\
\hline Adj. $R^{2}$ & 0.09 & 0.21 & 0.22 & 0.24 & 0.28 & 0.30 \\
\hline $\mathrm{N}$ & 4241 & 4241 & 4241 & 4241 & 4241 & 4241 \\
\hline
\end{tabular}

Table 35: Price Deviation and Exchange Characteristics, LOW price-series

\begin{tabular}{|c|c|c|c|c|c|c|}
\hline & (i) & (ii) & (iii) & (iv) & (v) & (vi) \\
\hline $\begin{array}{l}\text { ID to Fund } \\
\text { ID to Fund } x \text { Low Share }\end{array}$ & $-1.16^{* * *}$ & $-1.06^{* * *}$ & $\begin{array}{l}-1.29^{* * *} \\
0.88^{* * *}\end{array}$ & $-1.05^{* * *}$ & $-1.16^{* * *}$ & $\begin{array}{l}-1.53^{* * *} \\
1.18^{* * *}\end{array}$ \\
\hline Fixed Cost to Trade & & $0.09^{*}$ & $0.15^{* *}$ & -0.02 & -0.07 & 0.09 \\
\hline Free Trade Feasible & & $0.78^{* * *}$ & $0.75^{* * *}$ & $0.60 * * *$ & $0.96^{* * *}$ & $0.99^{* * *}$ \\
\hline Low Global Share & & $0.20^{* * *}$ & $-0.12^{*}$ & $-0.14^{*}$ & 0.04 & $-0.32^{* * *}$ \\
\hline Trade Volume & & & & $-1.06^{* * *}$ & $-0.67 * * *$ & $-0.33^{* *}$ \\
\hline Volume $\mathrm{x}$ Fixed Cost & & & & & $-0.32 *$ & $-1.07 * * *$ \\
\hline Volume x Free Trade & & & & & $-2.21^{* * *}$ & $-2.72^{* * *}$ \\
\hline Volume x Low Share & & & & & $-169.98^{* * *}$ & $-227.45^{* * *}$ \\
\hline Constant & $-4.10^{* * *}$ & $-4.48^{* * *}$ & $-4.39^{* * *}$ & $-4.10^{* * *}$ & $-4.10^{* * *}$ & $-4.01^{* * *}$ \\
\hline Date fixed effect? & $\mathrm{Y}$ & $\mathrm{Y}$ & $\mathrm{Y}$ & $\mathrm{Y}$ & $\mathrm{Y}$ & $\mathrm{Y}$ \\
\hline Adj. $R^{2}$ & 0.13 & 0.18 & 0.19 & 0.20 & 0.22 & 0.24 \\
\hline $\mathrm{N}$ & 4233 & 4233 & 4233 & 4233 & 4233 & 4233 \\
\hline
\end{tabular}

Significance: ${ }^{* * *} 1 \%,{ }^{* *} 5 \%,{ }^{*} 10 \%$. 


\section{B.4.5 Controlling for possible autocorrelation in the residual}

Tables (36) and (37) reports the result from the OLS regression using Newey-West errors, allowing for autocorrelation in the residual up to lag length $\ell$. A Newey West with lag 0 is the same as robust standard errors reported in Table 11 (ii). All results regarding the ID to Fund remain statistically significant.

Table 36: Price Deviation and Exchange Characteristics, Regression (i), Newey-West Regression

\begin{tabular}{|c|c|c|c|c|c|c|c|c|c|c|c|c|c|c|c|}
\hline \multirow[b]{2}{*}{$\ell=$} & \multicolumn{3}{|c|}{ Open } & \multicolumn{3}{|c|}{ Close } & \multicolumn{3}{|c|}{ Weighted } & \multicolumn{3}{|c|}{ High } & \multicolumn{3}{|c|}{ Low } \\
\hline & 0 & 2 & 15 & 0 & 2 & 15 & 0 & 2 & 15 & 0 & 2 & 15 & 0 & 2 & 15 \\
\hline ID to Fund & $-1.38^{* * *}$ & $-1.38^{* * *}$ & $-1.38^{* * *}$ & $-1.34^{* * *}$ & $-1.34^{* * *}$ & $-1.34^{* * *}$ & $-1.22^{* * *}$ & $-1.22^{* * *}$ & $-1.22^{* * *}$ & $-1.64^{* * *}$ & $-1.64^{* * *}$ & $-1.64^{* * *}$ & $-1.16^{* * *}$ & $-1.16^{* * *}$ & $-1.16^{* * *}$ \\
\hline Constant & $-4.59^{* * *}$ & $-4.59^{* * *}$ & $-4.59 * * *$ & $-3.63^{* * *}$ & $-3.63^{* * *}$ & $-3.63^{* * *}$ & $-4.38^{* * *}$ & $-4.38^{* * *}$ & $-4.38^{* * *}$ & $-2.98^{* * *}$ & $-2.98^{* * *}$ & $-2.98 * * *$ & $-3.80^{* * *}$ & $-3.80^{* * *}$ & $-3.80^{* * *}$ \\
\hline Date fixed effect? & Y & Y & $\mathrm{Y}$ & $\mathrm{Y}$ & $\mathrm{Y}$ & $\mathrm{Y}$ & Y & Y & $\mathrm{Y}$ & Y & $\mathrm{Y}$ & $\mathrm{Y}$ & $\mathrm{Y}$ & $\mathrm{Y}$ & $\mathrm{Y}$ \\
\hline $\mathrm{N}$ & 4243 & 4243 & 4243 & 4243 & 4243 & 4243 & 4238 & 4238 & 4238 & 4241 & 4241 & 4241 & 4233 & 4233 & 4233 \\
\hline
\end{tabular}

Table 37: Price Deviation and Exchange Characteristics, Regression (ii), Newey-West Regression

\begin{tabular}{|c|c|c|c|c|c|c|c|c|c|c|c|c|c|c|c|}
\hline & & Open & & & Close & & & Weighted & & & High & & & Low & \\
\hline$\ell=$ & 0 & 2 & 15 & 0 & 2 & 15 & 0 & 2 & 15 & 0 & 2 & 15 & 0 & 2 & 15 \\
\hline ID to 1 & $22^{* * * *}$ & $-1.92 * * *$ & $-1.92^{* * * *}$ & $79^{* * * *}$ & $-1.79 * * *$ & $79 * * *$ & $53 * * *$ & $-1.53^{* * * *}$ & $1.53^{* * * *}$ & $2.27 * * *$ & $-2.27 * * *$ & $-2.27^{* * * *}$ & $-1.53^{* * * *}$ & $-1.53^{* * *}$ & $-1.53^{*} y=$ \\
\hline I & & -0 . & & & & & & & & & & & & & \\
\hline tare & 1. & 1.5 & & & 1. & & & & & & $1.25^{* * *}$ & & & $1.18^{* * * *}$ & \\
\hline Trade & -0 & $-0.33^{* *}$ & -0 & & $-0.39^{* *}$ & & -0.58 & -0.58 & $-0.58 * *$ & & $-0.74 * * *$ & $-0.74^{* *}$ & $-0.33^{* *}$ & $-0.33^{*}$ & -0.33 \\
\hline Fixed Trading Costs & & -0.12 & -0 & & 0.05 & 0.05 & 0. & 0.01 & 0.01 & & $-0.83 * * *$ & **** & 0.09 & 0.09 & 0.09 \\
\hline ixed Trading & & $-1.02 * * *$ & -1 . & *** & $-1.07 * * *$ & & ;*** & $-0.73 *$ & & & $-0.74 *$ & & $-1.07^{* * * *}$ & $-1.07^{* * * *}$ & $-1.07^{* * *}$ \\
\hline Free $]$ & 0. & $0.83^{*}$ & 0 & 0.8 & $0.82^{*}$ & 0.82 & 0.78 & 0.78 & $0.78^{*}$ & 1.86 & 1.86 & 1.8 & $0.99^{*}$ & $0.99^{* * * *}$ & 0.99 *** \\
\hline & & $-3.06^{*}$ & & -2.56 & -2.56 & & & & & & -5.0 & & & $-2.72^{* * * *}$ & -2.72 \\
\hline Volume $x$ Low Share & $-167.55^{* * * *}$ & $-167.55^{* * *}$ & $-167.55 * * *$ & $-248.08 * * *$ & $-248.08 * * *$ & $-248.08 * * *$ & $-159.61 * * *$ & $-159.61 * * *$ & $-159.61 * * *$ & $-160.24^{* * *}$ & $-160.24^{* *}$ & $-160.24^{*}$ & $-227.45^{* * * *}$ & $-227.45 * * *$ & $-227.45 * *$ \\
\hline Constant & $-4.43^{* * *}$ & $-4.43^{* * *}$ & -4.4 & $-3.61 * * *$ & $-3.61 * * *$ & $-3.61 * * *$ & $-4.31 * * *$ & -4.31 *** & $-4.31 * * *$ & $-2.67 * * *$ & $-2.67 * * *$ & $* * *$ & $-3.83^{* * *}$ & $-3.83^{* * *}$ & ** \\
\hline 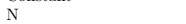 & 4243 & 4243 & 4243 & 4243 & 4243 & 4243 & 4238 & 4238 & 4238 & 4241 & 4241 & 4241 & 4233 & 4233 & 4233 \\
\hline
\end{tabular}

